\title{
Research Article Effects of Impeller Diameter on High-Speed Rescue Pump
}

\author{
Yuxing Bai, ${ }^{1}$ Fanyu Kong, ${ }^{1}$ Bin Xia, ${ }^{1}$ Fei Zhao, ${ }^{1,2}$ and Yingying Liu ${ }^{1}$ \\ ${ }^{1}$ National Research Center of Pumps, Jiangsu University, Zhenjiang, Jiangsu 212013, China \\ ${ }^{2}$ College of Mechanical Engineering, Wuxi Institute of Technology, Wuxi, Jiangsu 214121, China \\ Correspondence should be addressed to Yuxing Bai; yxbai1012@163.com
}

Received 25 May 2017; Revised 1 October 2017; Accepted 1 November 2017; Published 29 November 2017

Academic Editor: Andrea L. Facci

Copyright (C) 2017 Yuxing Bai et al. This is an open access article distributed under the Creative Commons Attribution License, which permits unrestricted use, distribution, and reproduction in any medium, provided the original work is properly cited.

\begin{abstract}
Impeller diameter is a crucial design parameter of high-speed rescue pumps because it affects the performance and inner flow characteristics of these pumps. In this study, a pump with an impeller diameter of $248 \mathrm{~mm}$ was modeled and its performance was tested. Numerical simulations were conducted under steady and unsteady states, in which the sizes of the impeller diameters were designated as $248 \mathrm{~mm}$ (original), $235.6 \mathrm{~mm}$ ( $5 \%$ trimmed), $223.2 \mathrm{~mm}$ (10\% trimmed), and $210.8 \mathrm{~mm}$ ( $15 \%$ trimmed). ANSYS software was used to test the shear stress transport (SST $k-\omega$ ) of the four models, and results agreed well with experimental data. Diameter size affected impeller characteristics in both steady and unsteady states. Subsequently, the differences in performance, hydraulic loss, pressure pulsation, and radial force of the impellers were evaluated. In the performance test, the head and efficiency of the pump decreased as impeller diameter was reduced. The result trends are in accordance with the trim law within the acceptable error range. In terms of hydraulic loss, the impeller and diffuser vane components presented opposite trends with flow rate increase. Finally, in terms of pressure pulsation and radial force, the amplitude diminished while periodicity improved as impeller diameter decreased.
\end{abstract}

\section{Preface}

The number of mining flooding accidents has increased in China and in other countries, and rescue operation groups have since demanded for lower-volume, higher-powered, and higher-speed pumps compared with conventional types. The current rescue pumps used for mining flooding are the multistage types, which have sufficient power and head to alleviate flooding from the bottom to the ground, but are complex and too large to use in narrow mining wells [1-4]. Consequently, the research groups at Jiangsu University that are in charge of rescue pump development have designed a series of smallvolume, high-powered, and high-speed rescue pumps that can be easily used during mining flooding incidents.

In recent years, computational fluid dynamics (CFD) analysis has been applied to the hydrodynamic design of several pump types due to the following reasons. First, the outcomes of hydraulic design and performance are difficult to predict because of complex geometric parameters. Second, constructing and testing physical prototypes are expensive and time-consuming endeavors, which reduce the profit margins of pump manufacturers. Consequently, several studies have been conducted on CFD to serve as guides for pump design and optimization [5-14]. In terms of pressure pulsation and radial force, Gao et al. [15] studied the static performance and pressure fluctuation of a large centrifugal pump and determined the main frequency of mine monitoring points; their findings agreed well with experimental data. Zhang et al. [16] investigated a conventional spiral volute pump and demonstrated how slope volute contributes to the significant decline of pressure pulsation. Pei et al. [17-19] investigated the flow unsteadiness behavior of a centrifugal pump and reported the significant effect of flow rate on time-averaged unsteadiness and distribution of turbulence intensity.

The impeller diameter is a crucial design parameter because it can easily affect the performance of pumps [20-23]. Jain et al. [24] proposed an empirical correlation to predict the efficiency of pump impellers that run in turbine mode. Barrio et al. [25] compared the effects of four impeller diameter sizes on pressure pulsation. Šavar et al. [26] proposed a maximum diameter trim value for pumps operating under a certain law. Wang and Liu [27] demonstrated the distribution of pressure and velocity in pumps with different impeller 


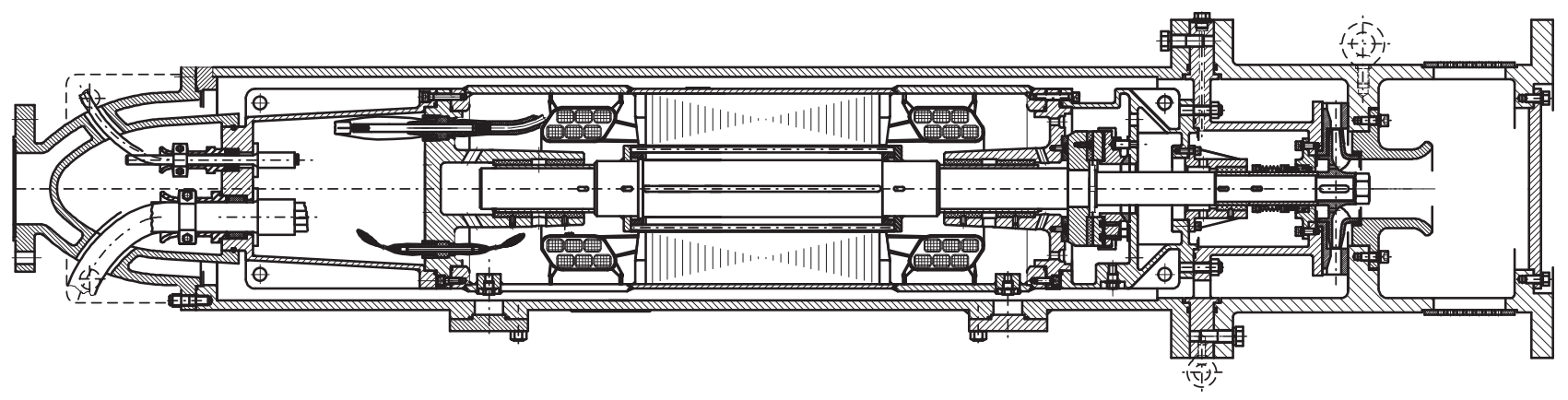

(a) Assembly of the model rescue pump

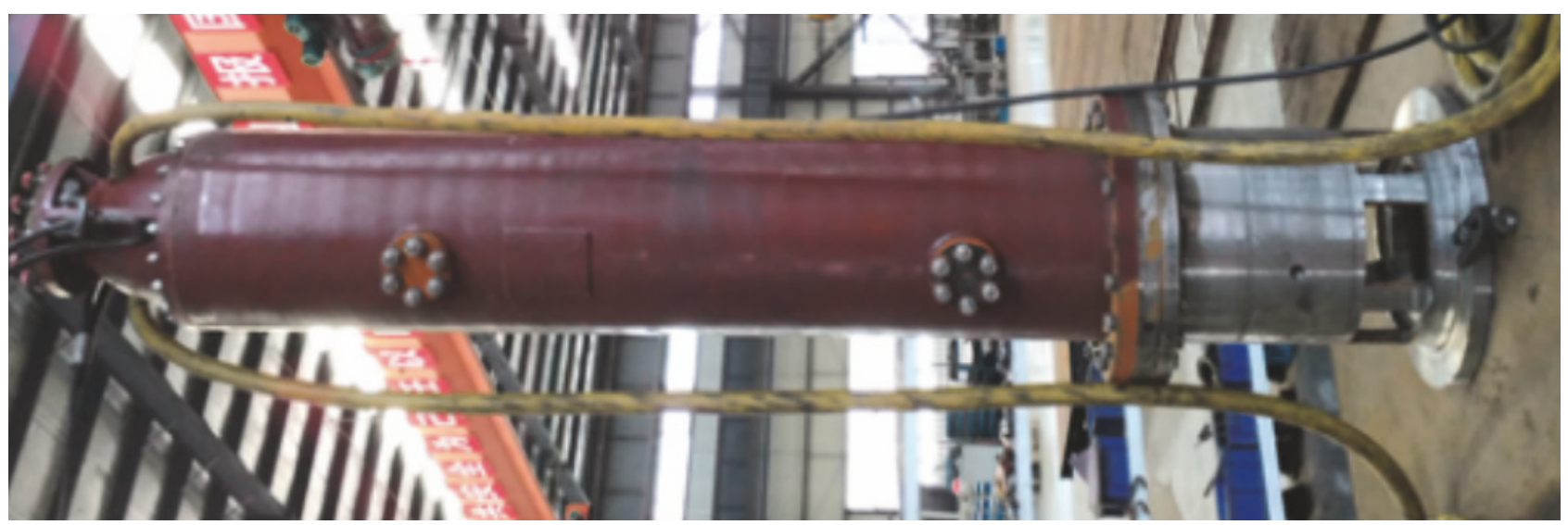

(b) External view of the model rescue pump

Figure 1: Model of rescue pump.

diameters. Zhang et al. [28] tested the impeller cutting law of double-channel pumps. Zhou et al. [29] compared a number of special impeller trimming methods for centrifugal pumps and offered a scientific basis for impeller trimming. Yates and Weybourne [30] proved that the enhanced performance of pumps is influenced by pump selection, impeller trimming, and speed drive variations.

However, the majority of the aforementioned studies have focused on low- or normal-speed pumps. Studies on the impeller diameters of high-speed and high-powered pumps remain scarce. Consequently, the current work presents an analytical method for investigating the effects of impeller diameters.

To achieve this objective, a low-volume, high-powered, and high-speed pump with a specific impeller diameter was designed. Subsequently, by changing diameter size, the original and three additional impellers were modeled and simulated using the CFD method. The results of the numerical simulation were verified and compared with experimental benchmarks. The four modeled impellers with different diameters were investigated in terms of pump performance and certain transient characteristics. Lastly, the laws of impeller diameter effect were determined to serve as guides for future theoretical designs and engineering applications.

\section{Main Parameters of the Reference Pump}

The pump investigated in this study was GPQ200-300, which is a typical high-speed rescue pump. The design parameters
TABLE 1: Main parameters of original high speed rescue pump.

\begin{tabular}{lccc}
\hline \multicolumn{4}{c}{ GPQ200-300 } \\
\hline$Q_{d}\left(\mathrm{~m}^{3} / \mathrm{h}\right)$ & $H_{d}(\mathrm{~m})$ & $N(\mathrm{rpm})$ & $n_{s}$ \\
\hline 200 & 300 & 6000 & 71.46 \\
\hline \multicolumn{2}{c}{ Impeller } & \multicolumn{2}{c}{ Diffuser vane } \\
\hline$D_{0} / \mathrm{mm}$ & 65 & $D_{3} / \mathrm{mm}$ & 253 \\
$D_{1} / \mathrm{mm}$ & 125 & $D_{4} / \mathrm{mm}$ & 360 \\
$D_{2} / \mathrm{mm}$ & 248 & $D_{5} / \mathrm{mm}$ & 310 \\
$\beta_{i 2} /{ }^{\circ}$ & 32 & $\alpha_{d 3} /{ }^{\circ}$ & 11.4 \\
$b_{2} / \mathrm{mm}$ & 15 & $a_{3} / \mathrm{mm}$ & 22 \\
$\gamma / /^{\circ}$ & 135 & $a_{4} / \mathrm{mm}$ & 30 \\
$Z_{1}$ & 7 & $Z_{2}$ & 9 \\
\hline
\end{tabular}

are provided in Table 1, and the model is presented in Figure 1. The nomenclature of all the symbols, including scalars and vectors, is listed in Nomenclature.

\section{Test Rig}

The test rig was acquired from the Hefei Hengda Group (China) (Figure 2). The pump was driven by a transducer that transferred current from the power network at a frequency range of $50-100 \mathrm{~Hz}$. Flow rate was adjusted through a valve located near the outlet duct of the pump. Flow magnitude was calculated using an LWGY-200A turbine flow meter with 


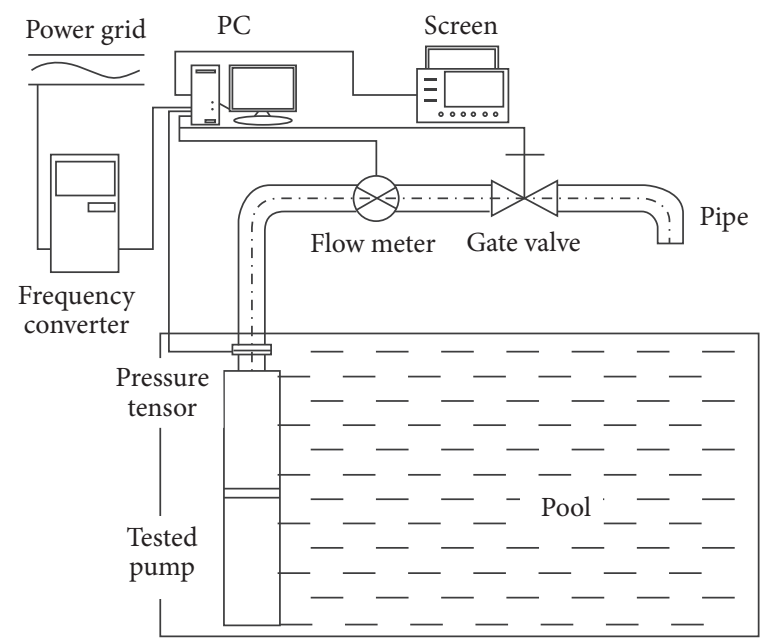

(a) Design diagram
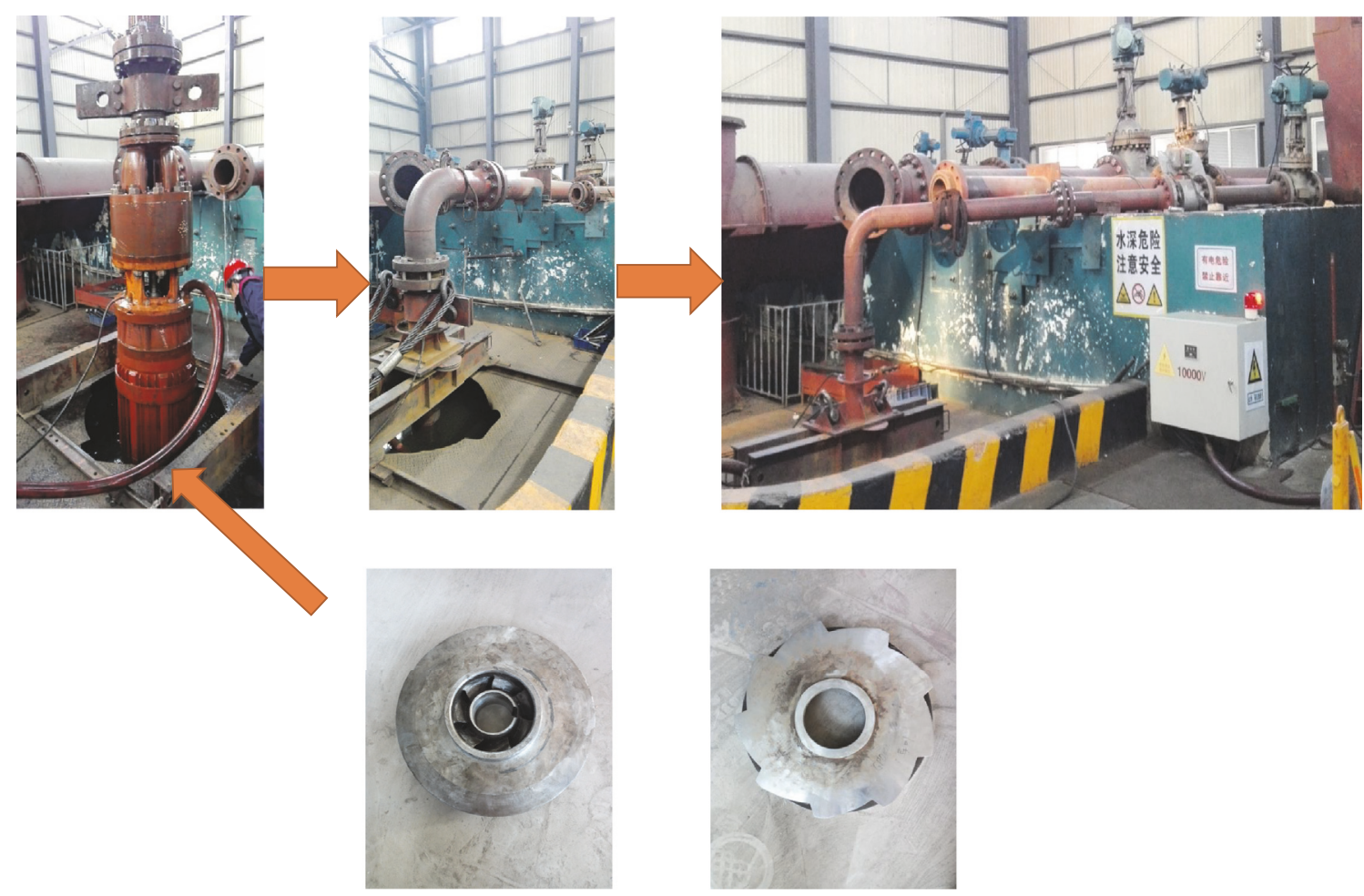

(b) Test site

Figure 2: Test rig.

a measurement uncertainty of $0.5 \%$. The inlet and outlet sections of the pump were affixed to two WT200 intelligent pressure tensors that collected mean static pressure at $0.1 \%$ uncertainty. Finally, the electric signal and input power were measured from the transducer, which was connected to a computer equipped with data acquisition software.

In addition, the test was carried out according to Chinese National Precision Grade Number 2 regulations which can be seen in Table 2.

The performance curves of the test rig are shown in Figure 3. The pump performed at the optimum and close
TABLE 2: Test precision standard of grade 2 in China.

\begin{tabular}{lcccc}
\hline Contents & $Q$ & $H$ & $P$ & $\eta$ \\
\hline Uncertainty & $\leqq \pm 2.0 \%$ & $\leqq \pm 1.5 \%$ & $\leqq \pm 1.5 \%$ & $\leqq \pm 2.8 \%$ \\
\hline
\end{tabular}

to the design point based on the experimental results. The pump head decreased when flow exceeded the design point. This condition might have been caused by the extraordinarily high speed and high power of the pump. Simultaneously, impact loss manifested as high flow rates due to the limited 
TABLE 3: Mesh groups for independence verification.

\begin{tabular}{lccccccc}
\hline Plan number & Impeller & Diffuser vane & Mesh Number (thousand) & & \\
domain & Inlet domain & Outlet domain & $\begin{array}{c}\text { Gap of front } \\
\text { cover }\end{array}$ & $\begin{array}{c}\text { Gap of back } \\
\text { cover }\end{array}$ & Total number \\
\hline 1 & 72.16 & 58.57 & 3.54 & 19.86 & 5.35 & 20.21 & 179.69 \\
2 & 194.95 & 160.80 & 5.74 & 57.43 & 15.61 & 50.12 & 484.65 \\
3 & 673.85 & 602.99 & 29.77 & 200.56 & 57.12 & 205.54 & 1769.83 \\
4 & 1322.69 & 931.78 & 37.55 & 315.68 & 91.91 & 308.86 & 3008.47 \\
5 & 1846.37 & 2058.27 & 88.47 & 705.61 & 321.87 & 725.86 & 5746.45 \\
\hline
\end{tabular}

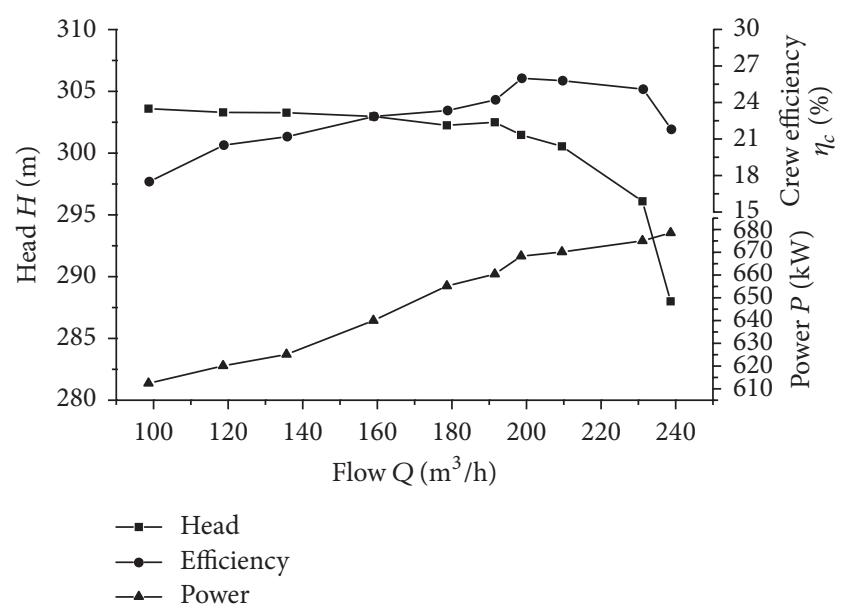

FIGURE 3: Experimental results.

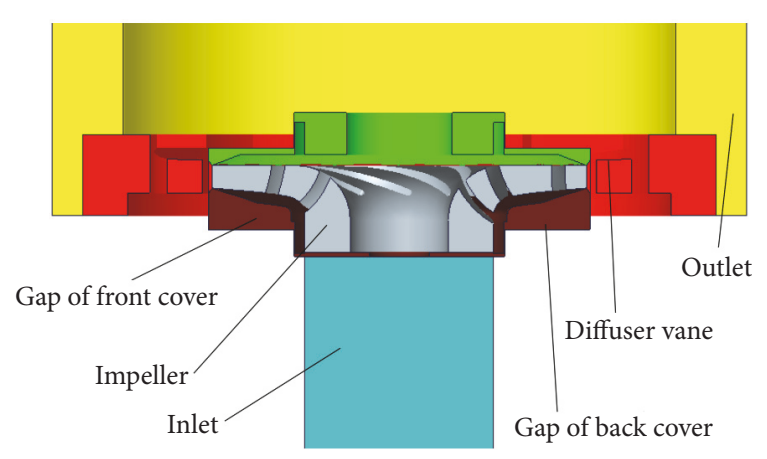

Figure 4: 3D model of fluid domain.

components of overflow. When the deviation from the design point is significant, the performance impact is more drastic. In the experiment, "efficiency" was represented by crew efficiency and measured in terms of power transmitted by the converter output. Overall, pump performance matched the requirements of the design.

\section{Numerical Model}

4.1. 3D Model. The 3D model of the entire flow passage was built in CREO 2.0. A sectional view of the model is shown in Figure 4. The computational domain of the numerical simulation comprised six parts: the inlet, the impeller, the

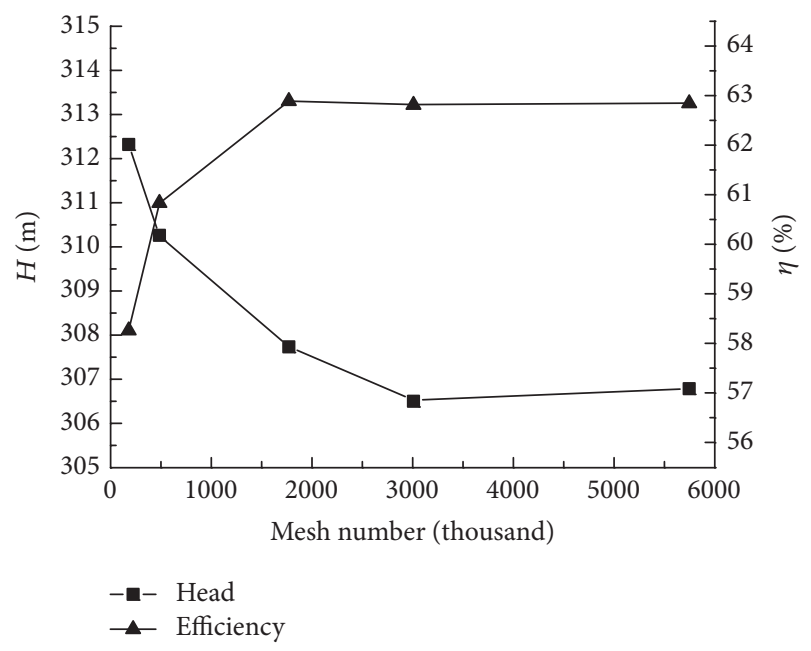

FIgURE 5: Mesh independence verification.

diffuser vane, the outlet, the gap of the front cover, and the gap of the back cover.

4.2. Mesh Independence Study. The accuracy of the numerical simulation was significantly affected by the quality of the meshes. The computational domain was generated via ANSYS-ICEM 14.5 using a structured hexahedral mesh; this setup was selected because of its minor truncation errors and good convergence. To achieve the best balance between calculation accuracy and time-cost point, the setup was tested for mesh independence. Table 3 lists the five groups of mesh structures that are used for the mesh independence study, while Figure 5 shows the simulation results of each group with a specific mesh number. Simulation accuracy and calculation time were determined; then the case with 1769.83 thousand cells was selected for the final simulation. In all parts of the mesh region, the $y+$ values were lower than 50 , which imply adequate coverage of the critical regions in the computational domain (Figure 6).

4.3. Boundary Condition. The steady and transient flow fields of the domain were solved using the CFD code of ANSYS CFX14.5. Before unsteady flow simulations were conducted, steady calculations were performed. A frozen rotor interface connected to the rotating and stationary parts of the pumps were used for the calculations. Then, the inlet and outlet 


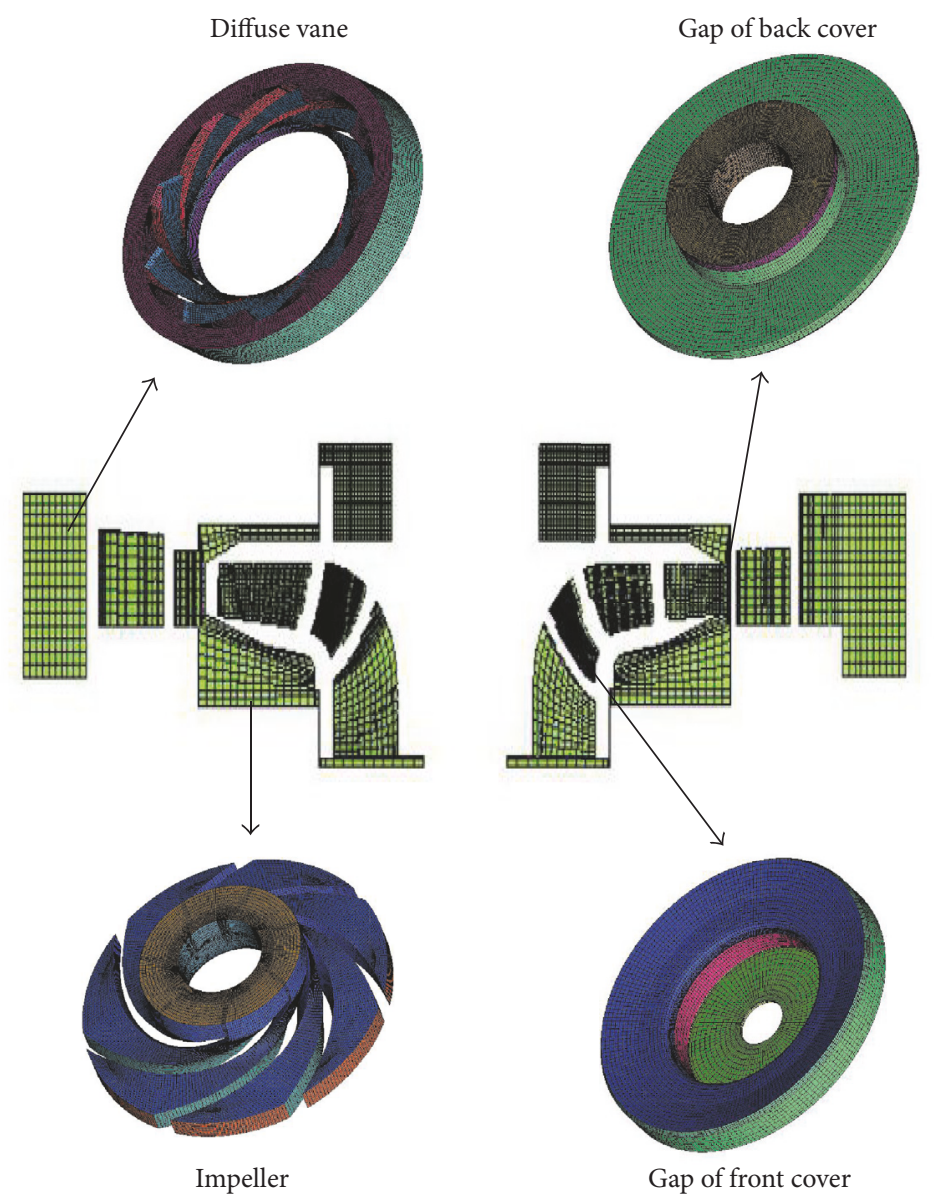

FIGURE 6: Mesh of fluid domain.

sections were set for total pressure rate and mass flow rate, respectively. To obtain exact results, the inlet was extended to five times the length of the outlet. Meanwhile, in the steady simulation, the physical timescale of $5 / \omega$ was set as the timescale control, whereas the roughness of the solid walls was designated as no-slip with $25 \mu \mathrm{m}$. Thereafter, the converged numerical solution for the steady state was used as the initial condition of the unsteady-state calculations. During simulation, time step $\Delta t$ was set to a series of $3^{\circ}$ changes in the impeller circumference; different rotation speeds were also applied. Total time was set to a minimum of 10 full impeller revolutions. Lastly, the maximum residual of the convergence criterion was set to $1 \times 10^{-5}$ in accordance with the high resolution scheme for time discretization. Besides, the second-order backward Euler for the transient scheme.

4.4. Turbulence Model. Flow field was analyzed in CFX using the URANS equations with the following governing equations [31-34]:

\section{Continuity Equation}

$$
\frac{\partial u_{i}}{\partial x_{j}}=0
$$

Navier-Stokes Equations

$$
\rho\left(\frac{\partial u_{i}}{\partial t}+u_{j} \frac{\partial u_{i}}{\partial x_{j}}\right)=-\frac{\partial p}{\partial x_{i}}+\frac{\partial}{\partial x_{j}}\left(\mu \frac{\partial u_{i}}{\partial x_{j}}-\rho \overline{u_{i}^{\prime} u_{j}^{\prime}}\right),
$$

where $u$ is the flow velocity, $\mu$ is the dynamic viscosity, $\rho$ is density, and $\rho \overline{u_{i}^{\prime} u_{j}^{\prime}}$ is Reynolds stress.

To derive the solutions for real flows, the numerical approach was adopted; that is, equations were replaced with algebraic approximations so they could be solved numerically. When the conservation equations for mass, momentum, and passive scalar were considered, the finite volume method was expressed in the Cartesian coordinates as follows [31-33]:

$$
\begin{aligned}
& \frac{\partial \rho}{\partial t}+\frac{\partial}{\partial x_{j}}\left(\rho \vec{U}_{j}\right)=0, \\
& \frac{\partial}{\partial t}\left(\rho \vec{U}_{j}\right)+\frac{\partial}{\partial x_{j}}\left(\rho \vec{U}_{j} \vec{U}_{i}\right) \\
& \quad=-\frac{\partial p}{\partial x_{i}}+\frac{\partial}{\partial x_{j}}\left[\mu_{\mathrm{eff}}\left[\frac{\partial \vec{U}_{i}}{\partial x_{j}}+\frac{\partial \vec{U}_{j}}{\partial x_{j}}\right]\right], \\
& \frac{\partial}{\partial t}(\rho \varphi)+\frac{\partial}{\partial x_{j}}\left(\rho \vec{U}_{j} \varphi\right)=\frac{\partial}{\partial x_{j}}\left[\Gamma_{\mathrm{eff}}\left[\frac{\partial \varphi}{\partial x_{j}}\right]\right]+S_{\varphi},
\end{aligned}
$$




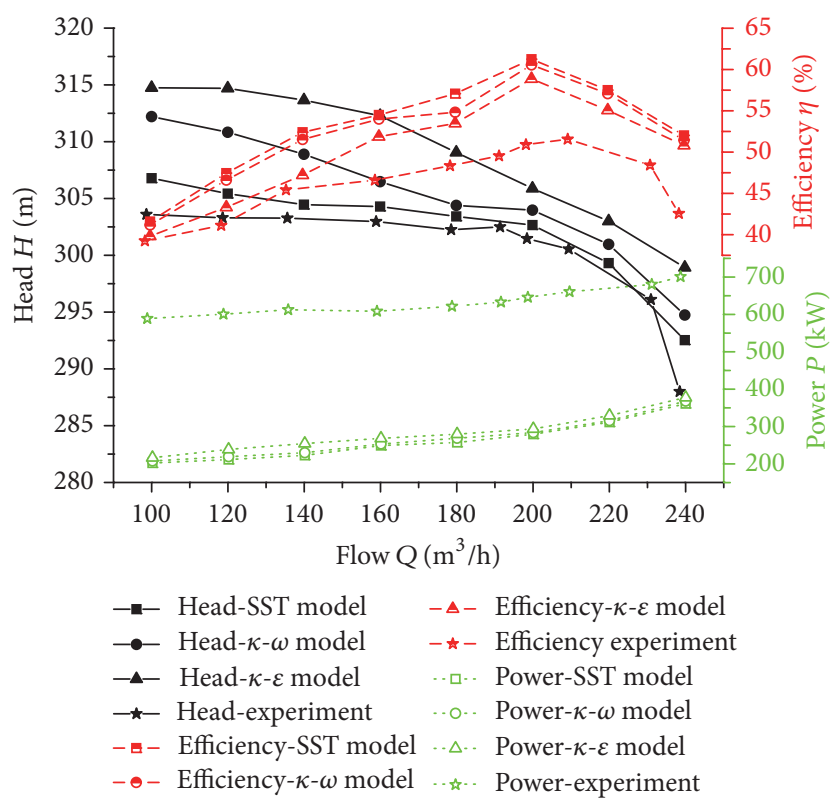

Figure 7: Comparison between experiment and numerical simulation.

where $\mu_{\text {eff }}$ is effective viscosity, $\Gamma_{\text {eff }}$ is effective diffusivity, $\varphi$ is time varying component, $\vec{U}$ is vector of velocity, $S_{\varphi}$ is sum of the body forces.

Furthermore, Reynolds stress was calculated using the turbulence model. In general, the turbulence model significantly affects the accuracy and precision of a simulation when CFD is used. In this study, the turbulence model comprised three models, namely, $k-\omega, k-\varepsilon$, and SST $k$ - $\omega$, to complement the numerical simulation. Thereafter, the simulation results were compared with experimental data.

Hydraulic efficiency was determined from the numerical simulation, but it differed from the crew efficiency mentioned in the experimental data. Thus, crew efficiency was transformed into a hydraulic efficiency value by multiplying the mechanical value by the volumetric efficiency value. Consequently, the efficiency indicator was applied to validate simulation accuracy. In addition, the power acquired from the simulation was hydraulic power, which differed from the input power obtained in the experimental data. These two types of power (i.e., energy indicators) can reflect the tendency to change the unit condition of the pump. The aforementioned head and power parameters were compared to validate simulation accuracy.

Figure 7 shows the comparative results of the experimental data and the numerical simulation. At certain points, the simulation results differed from the experimental data because of the following reasons. (1) In the numerical simulation, the flow in the inlet was considered a uniform flow, which differed from the actual flow condition. (2) Some components of the flow passage were cast parts with a rough surface and, thus, might have affected wall flow. (3) The effects of mesh quality, boundary condition, and turbulence model were difficult to investigate in complex flow simulations. Despite the aforementioned limitations, the performance curves of the simulation are generally consistent with experimental data, thereby proving the reliability of the simulation. The head result of the SST $k-\omega$ model is extremely close to the experimental result. Consequently, all the numerical simulations were based on the SST $k-\omega$ model.

The SST $k-\omega$ model could be expressed [31-33]:

$$
\begin{aligned}
& \frac{\partial(\rho k)}{\partial t}+\frac{\partial}{\partial x_{j}}\left(\rho \vec{U}_{j} k\right) \\
& =\frac{\partial}{\partial x_{j}}\left[\left(\mu+\frac{\mu_{t}}{\sigma_{k 3}}\right) \frac{\partial k}{\partial x_{j}}\right]+P_{k}-\beta^{\prime} \rho k \omega+P_{k b}, \\
& \frac{\partial(\rho \omega)}{\partial t}+\frac{\partial}{\partial x_{j}}\left(\rho \vec{U}_{j} \omega\right) \\
& =\frac{\partial}{\partial x_{j}}\left[\left(\mu+\frac{\mu_{t}}{\sigma_{\omega 3}}\right) \frac{\partial \omega}{\partial x_{j}}\right] \\
& +\left(1-F_{2}\right) 2 \rho \frac{1}{\sigma_{\omega 2} \omega} \frac{\partial k}{\partial x_{j}} \frac{\partial \omega}{\partial x_{j}}+\alpha_{3} \frac{\omega}{k} P_{k}-\beta_{3} \rho \omega^{2} \\
& +P_{\omega b},
\end{aligned}
$$

where $P_{k}$ is the turbulence production due to viscous forces, $P_{k b}$ and $P_{\omega b}$ represent the influence of the buoyancy forces, $\beta^{\prime}$, $\alpha_{1}, \beta_{1}, \sigma_{k 1}, \sigma_{\omega 1}, \sigma_{k 2}, \sigma_{\omega 2}, \alpha_{2}, \beta_{2}, \alpha_{3}, \beta_{3}, \sigma_{\omega 3}$ are constant, $u$ is the flow velocity, $\mu$ is the dynamic viscosity, $\rho$ is density, and $F_{2}$ is blending functions.

$$
F_{2}=\tanh \left(\arg _{2}^{2}\right),
$$

with

$$
\arg _{2}=\max \left(\frac{2 \sqrt{k}}{\beta^{\prime} \omega y}, \frac{500 v}{\omega y^{2}}\right) .
$$

The boundary condition for the dissipation rate, $\varepsilon$, is then given by the following relation which is valid in the logarithmic region:

$$
\begin{aligned}
\varepsilon & =\frac{\rho u^{*}}{\widetilde{y}^{*} \mu} \frac{C_{\mu}^{3 / 4}}{\kappa} k^{3 /}, \\
\mu^{*} & =\max \left(C_{\mu}^{1 / 4} \sqrt{k}, \text { Coef } \cdot \frac{U_{t}}{\widetilde{y}^{*}}\right), \\
\tilde{y}^{*} & =\max \left(y^{*}, 11.06\right),
\end{aligned}
$$

where $C_{\mu}$ is $k-\varepsilon$ turbulence model constant, 0.09. $\kappa$ is Von Karman constant with value $0.4, y$ is wall distance, and Coef is the expert coefficient with the default value 0.01 .

Considering the rough wall condition, the scalable wall function $y^{+}$is defined as

$$
\begin{aligned}
& y^{+}=\max \left(y^{*}, h_{S}^{+} /, 11.06\right), \\
& y^{*}=\frac{\rho u^{*} \Delta y}{\mu} .
\end{aligned}
$$




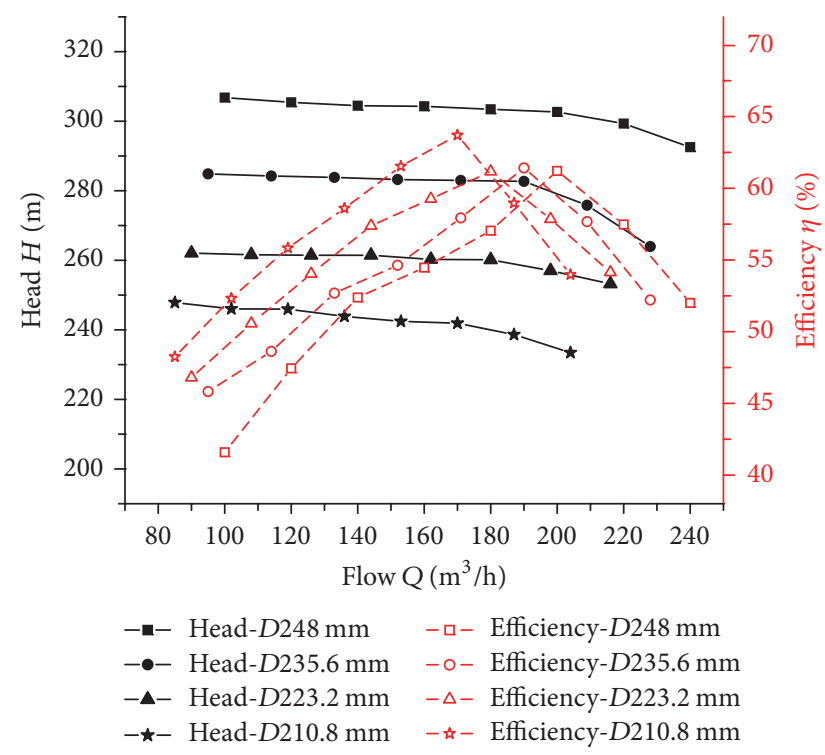

FIGURE 8: Comparison of performance curves.

$h_{S}{ }^{+}$is dimensionless sand-grain roughness, $\Delta n$ is the distance between the first and second grid point, $u^{*}$ is alternative velocity scale, and $y^{*}$ is alternative distance.

\section{Result Analysis}

To analyze the effect of impeller diameter on the performance of high-speed rescue pumps, simulations were performed using four impellers:
(1) Original impeller $(\Phi 248 \mathrm{~mm})$
(2) $5 \%$ trimmed impeller $(\Phi 235.6 \mathrm{~mm})$
(3) $10 \%$ trimmed impeller $(\Phi 223.2 \mathrm{~mm})$
(4) $15 \%$ trimmed impeller (

\subsection{Steady Analysis}

5.1.1. Performance Curves. To determine the effect of impeller diameter on performance, all simulations were conducted at flow rates of $0.5-1.2 Q_{d}$ (i.e., based on the law of impeller trim for an impeller diameter of $248 \mathrm{~mm}$ ). As shown by the performance curves in Figure 8, pump head and efficiency are in accord with the law of impeller trim as diameter decreases. In all four cases, the head curves gradually decreased when pump flow increased (i.e., before the design point); thereafter, the decreasing head curves became more evident (i.e., after the design point). Among the four cases, the head curve for the $235.6 \mathrm{~mm}$ impeller diameter presented the largest descending gradient. The findings suggest that high-velocity fluids, which were caused by impeller rotation during heavy flows, significantly affect impact loss in the gap area between the impeller inlet and the diffuser vane outlet. In addition, the velocity of the impeller with a diameter of $235.6 \mathrm{~mm}$ was higher than those of the impellers with diameters of $223.2 \mathrm{~mm}$ and $210.8 \mathrm{~mm}$. However, the gap area was smaller than those in the two other cases, and these conditions imply
TABLE 4: Difference between $H_{\mathrm{th}}$ and $H_{\mathrm{si}}$.

\begin{tabular}{lccc}
\hline$D_{2}(\mathrm{~mm})$ & $H_{\text {th }}(\mathrm{m})$ & $H_{\mathrm{si}}(\mathrm{m})$ & Error $(\%)$ \\
\hline 248 & 300 & 302.66 & 0.89 \\
235.6 & 270.75 & 282.70 & 4.69 \\
223.2 & 243 & 260.14 & 7.05 \\
210.8 & 216.75 & 241.95 & 11.63 \\
\hline
\end{tabular}

higher impact on the diffuser vane. The $248 \mathrm{~mm}$ impeller diameter (original model) was more adaptable under heavy flow conditions compared with the other three cases. In terms of efficiency, all four cases reached the maximum value of the design point, which correspond to the designated peak value for the smallest impeller diameter. In the case of high-rotation speeds, the impeller with the smallest diameter attained the least impact loss in the inlet of the diffuser vane.

Equations (9) were used as the theoretical equations for the heads of the different impellers. These equations were determined based on the original model and the trim law at the nominal flow point. To investigate accuracy from the perspective of theoretical progress, the difference between the theoretical head $\left(H_{\text {th }}\right)$ and the numerically simulated head $\left(H_{\mathrm{si}}\right)$ was established. As shown in Table 4, errors become apparent as impeller diameter increases; this finding implies a mismatch between theoretical and experimental results. However, these errors were within the acceptable range, and thus, the equations were applied to the head prediction of high-speed rescue pump design [33].

$$
\begin{aligned}
& \frac{Q^{\prime}}{Q}=\frac{D_{2}^{\prime} \pi b_{2}^{\prime} v_{m 2}^{\prime}}{D_{2} \pi b_{2} v_{m 2}}=\frac{D_{2}^{\prime} v_{m 2}^{\prime} b_{2}^{\prime}}{D_{2} v_{m 2} b_{2}}=\frac{D_{2}^{\prime}}{D_{2}}, \\
& \frac{H^{\prime}}{H}=\frac{u_{2}^{\prime} v_{m 2}^{\prime}}{u_{2} v_{m 2}}=\left(\frac{D_{2}^{\prime}}{D_{2}}\right)^{2} .
\end{aligned}
$$

5.1.2. Hydraulic Loss. To illustrate hydraulic loss in highspeed pumps, the flow domain was divided into three parts (Figure 9): the impeller region, the diffuser vane region, and the draft tube.

Total hydraulic loss $\left(H_{t}\right)$ and impeller hydraulic loss $\left(H_{\mathrm{im}}\right)$, which were obtained from the numerical simulations of the impellers with different diameters, are shown in Figure 10. In the four cases, total loss and impeller loss curves presented the same trend; that is, flow increase corresponds to rapidly descending curves. However, once the flow exceeds the nominal flow rate, the curves begin to move upward. In general, given the same flow point, increasing the impeller diameter causes the hydraulic loss value to increase.

In a high flow region, an increase in $H_{t}$ and $H_{\text {im }}$ was more evident in the impeller with $210.8 \mathrm{~mm}$ diameter compared with the other three cases. This phenomenon may be explained as follows. First, even if more fluid entered the gap between the impeller and the diffuser (i.e., high flow rate), this fluid remained in the gap and did not flow into the diffuser vane domain. Second, the efficiency rate of the impeller with $210.8 \mathrm{~mm}$ diameter decreased dramatically with heavy flow (Figure 10). 


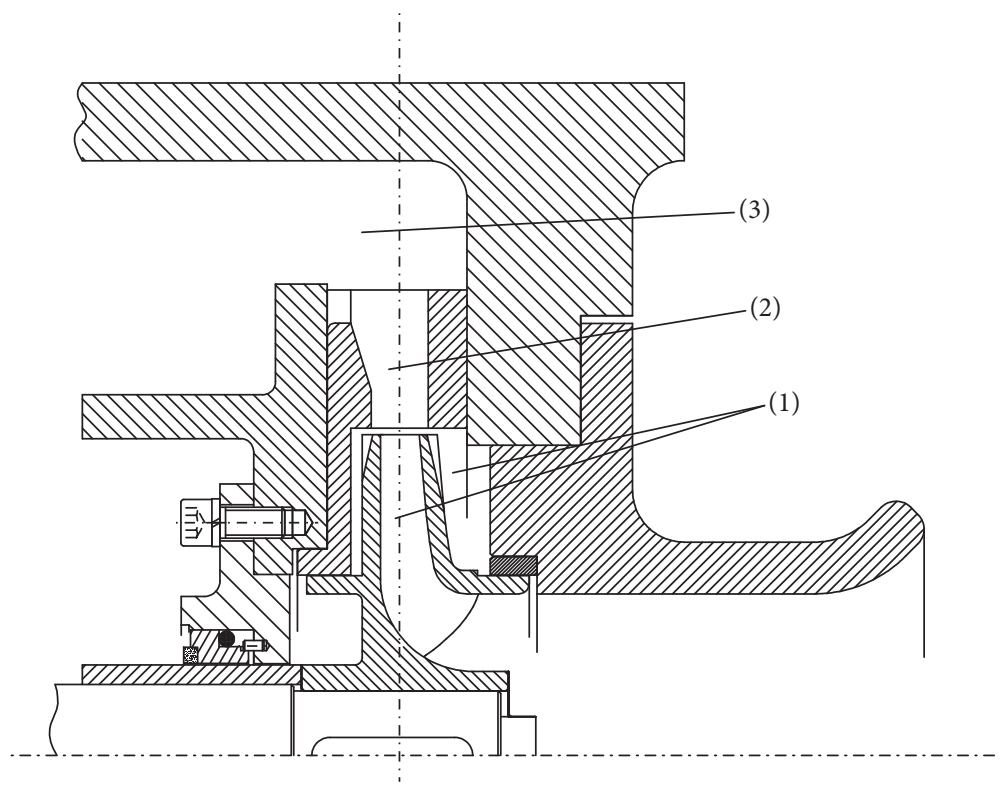

(1) Impeller region

(2) Diffuser vane region

(3) Draft tube

FIgUre 9: Division of hydraulic loss area.

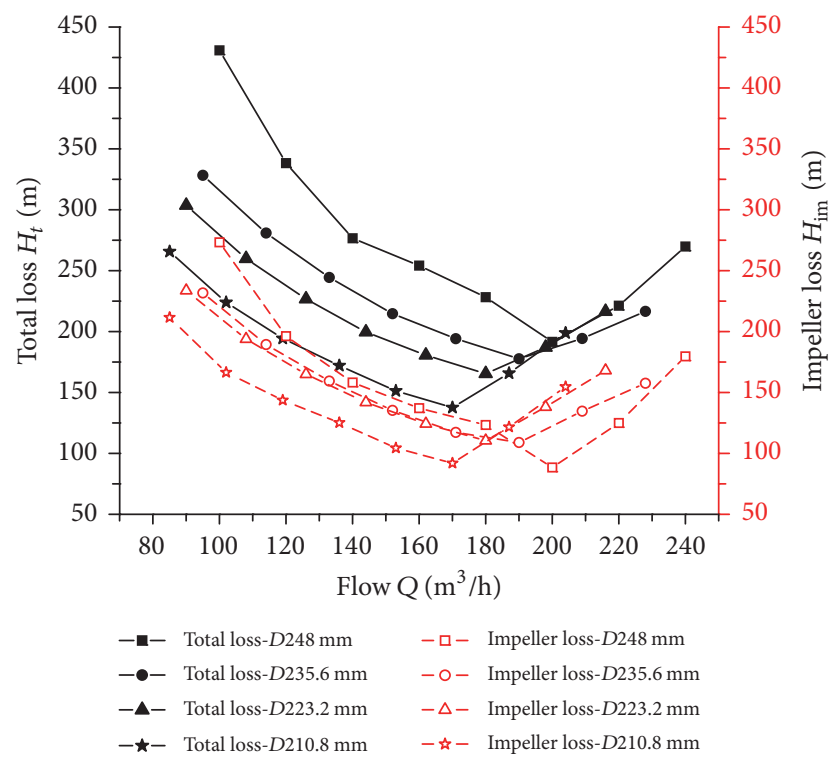

Figure 10: Hydraulic loss distribution.

In Figure 11, the proportions of the impeller and the diffuser vane in relation to total hydraulic loss are shown in Figure 11. Hydraulic loss in the impeller and the diffuser vane plays an important role in pump performance. The trends for the impeller with a diameter of $248 \mathrm{~mm}$ were more adverse compared with the other three cases.

The following points may elucidate the case of the impeller with a diameter of $248 \mathrm{~mm}$. First, hydraulic loss

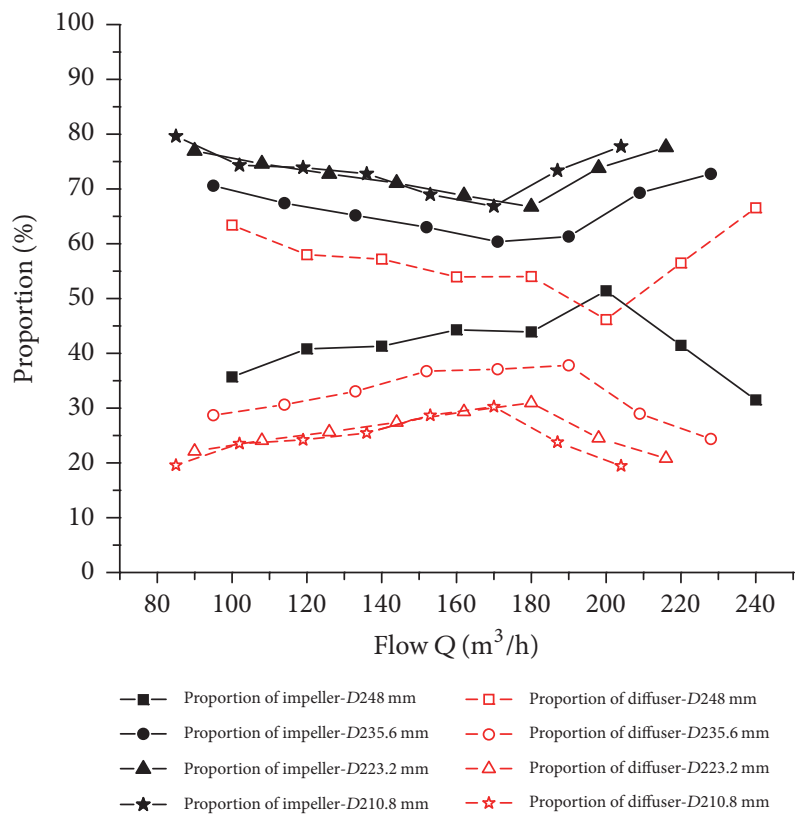

FIgURE 11: Proportion of hydraulic loss in impeller and diffuser.

in the impeller was smaller than that in the diffuser vane at each flow rate. Unlike in the diffuser vane passage, the flow in the impeller was smooth. Second, the proportion of the impeller in relation to total hydraulic loss increased with flow increase. Once the peak value in the design point was reached, the proportion decreased with continuous flow 


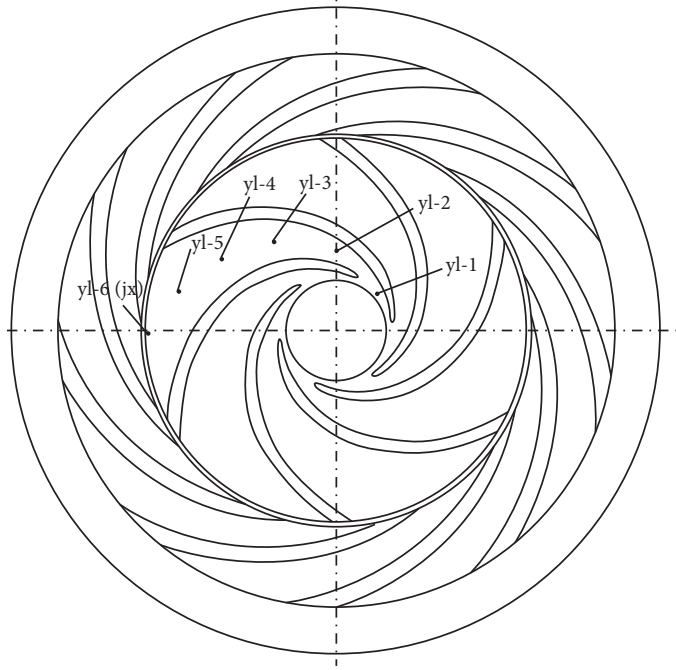

FIGURE 12: Monitors in impeller passage.

increase. Presumably, turbulence increased when pump flow increased. Finally, hydraulic loss in the diffuser vane initially decreased and then increased, and this behavior could be attributed to heavy flows that blocked the diffuser vane passage. The diffuser vane passage was divided into nine parts, thereby increasing the probability of blockage, which then resulted in higher loss for the diffuser vane than that for the impeller. At small rates (i.e., the other three cases), however, the loss in the impeller was considerably higher than that in the diffuser vane. This phenomenon may be ascribed to the mismatched characteristics of the impeller.

\subsection{Unsteady Analysis}

5.2.1. Pressure Pulsation. To complete the analysis of the flow state, the four cases were compared in terms of unsteady pressure and radial force state. In this study, all transient results were set from the sixth to the tenth period, thereby deriving relatively accurate data. To monitor flow, six points were designated at the middle flow line in the impeller flow passage. These points were evenly distributed along the radial location (Figure 12). Subsequently, monitoring point yl-6, which was initially placed in the impeller flow passage of the original pump, was repositioned in the gap between the impeller and diffuser vane in the other three cases. Monitoring point yl- 6 was also renamed jx in the other three models.

Pressure pulsation was caused by the comprehensive effect of rotor-stator interaction, turbulence, and reflux.

The pressure pulsation energy in the impeller flow passage was evaluated alongside the effects of amplitude errors. Subsequently, a pressure coefficient was added to (10) as follows:

$$
C_{p}=\frac{P-\bar{P}}{(1 / 2) \rho u_{2}^{2}}
$$

where $P$ represents static pressure at monitor point, $\bar{P}$ represents mean pressure, $\rho$ is density, and $u_{2}$ is velocity at the outlet of impeller.

Figure 13 shows the time history of unsteady pressure pulsations with nominal flow rates. From the perspective of periodicity, the pumps with impellers with diameters of $223.2 \mathrm{~mm}$ and $210.8 \mathrm{~mm}$ attained better cycles than the other two models. The periodicities of the impellers with diameters of $248 \mathrm{~mm}$ and $235.6 \mathrm{~mm}$ were not evident. This phenomenon may be explained by two reasons. On the one hand, a larger impeller diameter requires higher impeller outlet velocity and longer channels. However, this setup is prone to vortex or flow separation, which hampers flow periodicity. On the other hand, the values of $C_{P}$ in all the four cases increased when the location of a monitoring point moved from the impeller inlet to the outlet. The outlet of the impeller experienced higher velocity and larger vortex than the inlet because of the flow direction of the fluid from the impeller passage. Finally, the maximum $C_{P}$ of the impeller with $210.8 \mathrm{~mm}$ diameter was lower than those in the other three cases, and this finding may be related to the gap between the impeller and the diffuser vane. On the basis of the findings, increasing the gap area causes pressure pulsation to diminish. In addition, fluctuation amplitude becomes relatively small with the disappearance of the vortex or secondary flow in the buffer area.

Figure 14 shows the pressure spectra after fast Fourier transform (FFT). For the three impeller diameters (235.6, 223.2 , and $210.8 \mathrm{~mm}$ ), the rotating speed was $6000 \mathrm{rpm}$, the rotating frequency $\left(f_{n}\right)$ was $100 \mathrm{~Hz}$, and the blade passing frequency $\left(f_{B E F}=7 f_{n}\right)$ was $700 \mathrm{~Hz}$. The $0-2800 \mathrm{~Hz}$ frequency band $\left(4 f_{B E F}\right)$ played a predominant role in the pressure spectra in all the four cases. The frequency signals are related to the complex internal flow structure within this range. The effects caused by the rotor-stator interaction are also negligible, which implies that the values of the components at the blade passing frequency are relatively small. By contrast, in the case of the impeller with a diameter of $248 \mathrm{~mm}$, each order of $f_{B E F}$ played a dominant role in the pressure spectra. These findings suggest that the size of the gap between the impeller and the diffuser vane is related to rotor-stator interaction, which evidently affects flow.

The frequency amplitude of the impeller with a diameter of $210.8 \mathrm{~mm}$ was smaller than those of the other three cases. The unsteady vortex shedding effect was extensive in the case of the $210.8 \mathrm{~mm}$ impeller diameter due to the relatively large gap between the impeller and the diffuser vane and the short flow channel.

As shown in Figure 14, in the case of the $223.2 \mathrm{~mm}$ impeller diameter, at monitoring point $j x$, the amplitude peak appeared at each order of $f_{B E F}$ and the values were much bigger than the other frequencies. The reason is probably that the rotorstator interaction is extremely obvious in this case. As a resource of disturbance, the impeller may lead to the violent rise of pressure in the gap when the impeller passed the inlet of flow passage of diffuser vane. Apart from the interaction factor, the flow shedding and vortex shedding which may develop in this region were also contributed to the clear dominant peaks. Furthermore, the amplitude at monitoring point $\mathrm{jx}$ 

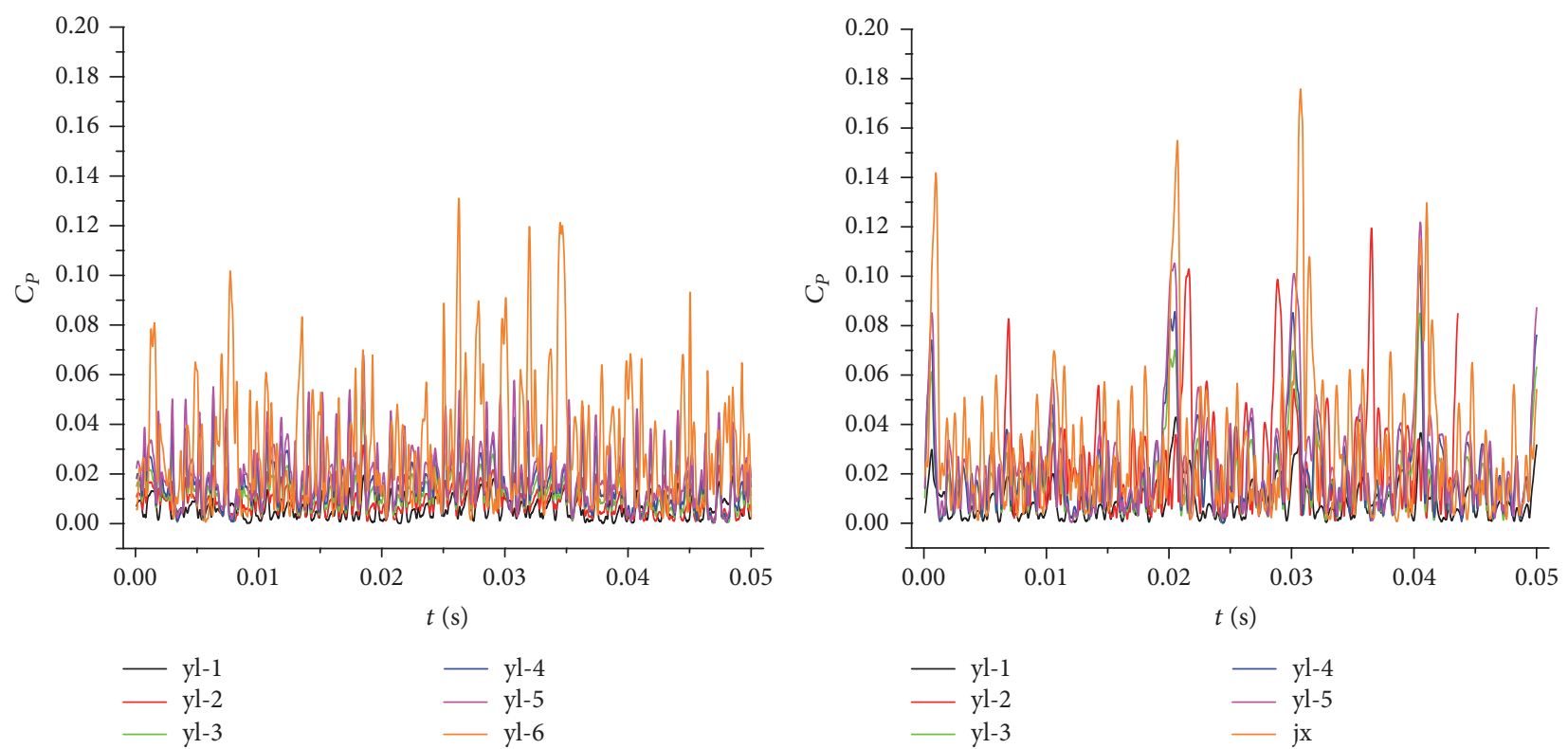

(b) $D_{2}=235.6 \mathrm{~mm}$

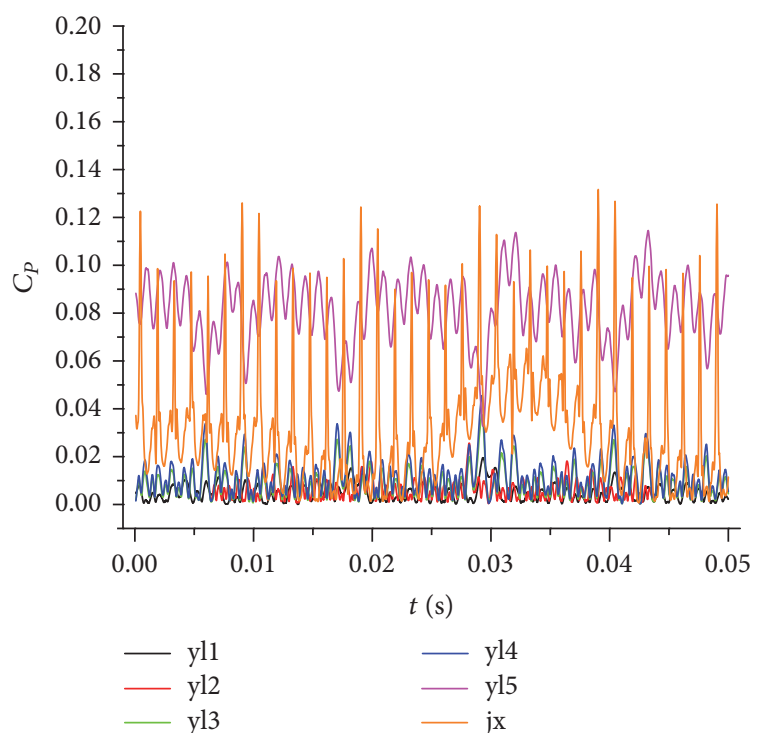

(c) $D_{2}=223.2 \mathrm{~mm}$

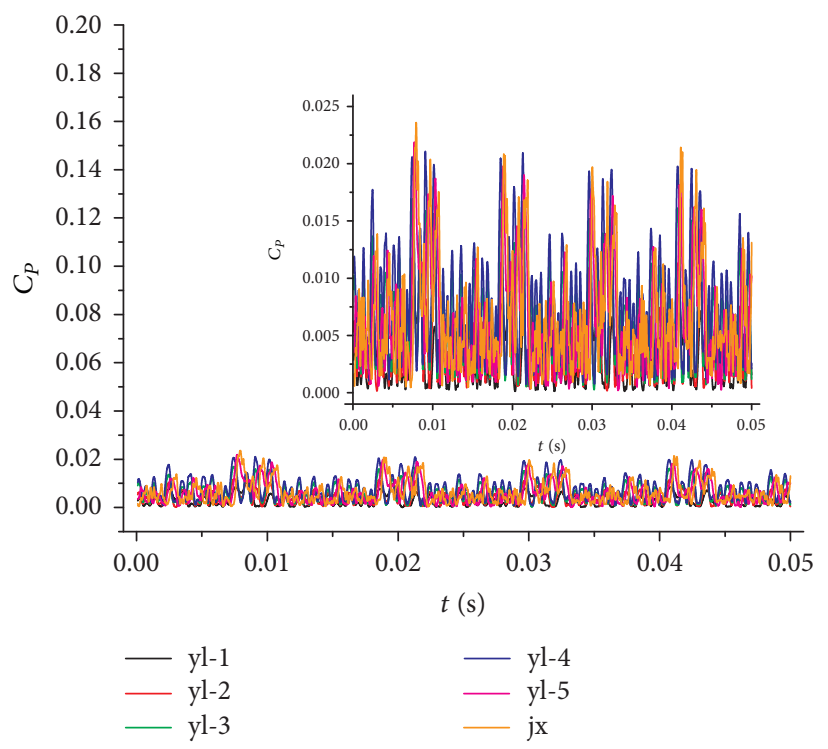

(d) $D_{2}=210.8 \mathrm{~mm}$

FIGURE 13: Time history of the pump with different impeller diameters at nominal flow rate.

of the $223.2 \mathrm{~mm}$ impeller diameter was considerably higher than those in the other two cases. The gap between the impeller and the diffuser was also relatively larger and the impeller channel was relatively shorter because of impeller trimming. Subsequently, the fluid in the passage was inadequate; otherwise, the unsteady factors (e.g., flow shedding and vortex shedding) near the wall were apparent. In general, unsteady flows continuously fill in the cutting gaps. However, an extremely small cutting gap area is insufficient to fully develop a vortex. Meanwhile, an extremely large cutting gap region completely absorbs an unstable vortex. In the present study, the fluctuation amplitude of the jx monitoring point reached the maximum value at the middle cutting margin.
5.2.2. Radial Force. In hydrodynamics, force is produced by fluid pressure and fluid viscosity. The effect of impeller eccentricity is neglected to accurately calculate force.

The effects of rotation position and time are considered. The radial force of the impellers used in this study comprised surface dispersion forces, as defined in (11) [34].

The forms are

$$
\begin{aligned}
& \vec{F}_{p}=-\int_{A} p \cdot e \cdot d A \\
& \vec{F}_{v}=-\mu \int_{A}\left(\frac{d \mu}{d n_{n}}\right) \cdot e \cdot d A \\
& \vec{F}_{r}=\vec{F}_{p}+\vec{F}_{v},
\end{aligned}
$$




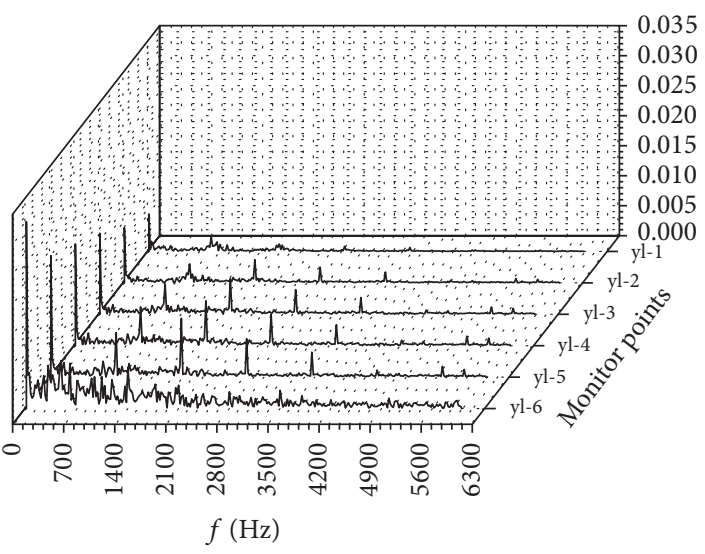

(a) $D_{2}=248 \mathrm{~mm}$

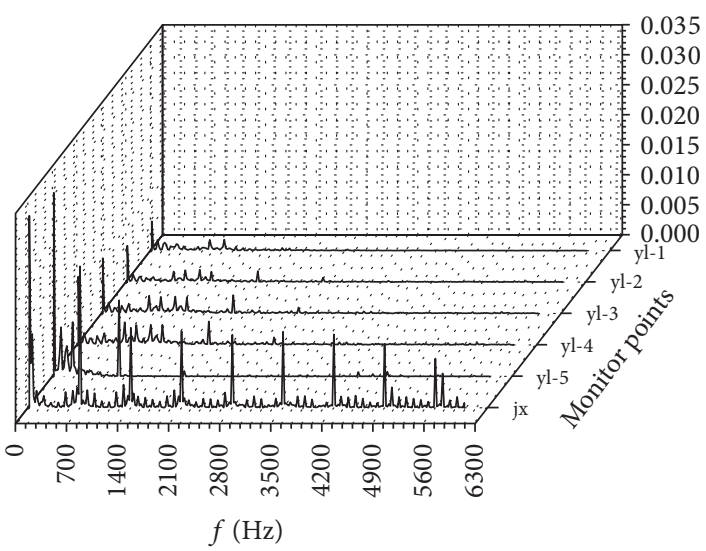

(c) $D_{2}=223.2 \mathrm{~mm}$

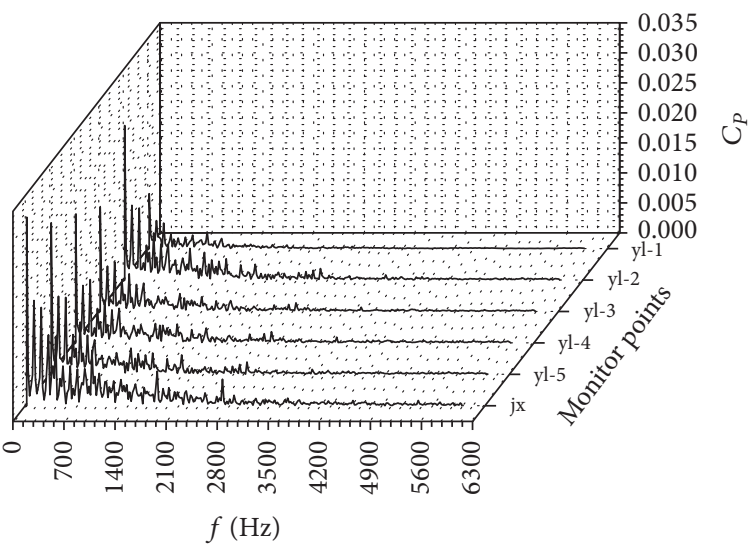

(b) $D_{2}=235.6 \mathrm{~mm}$

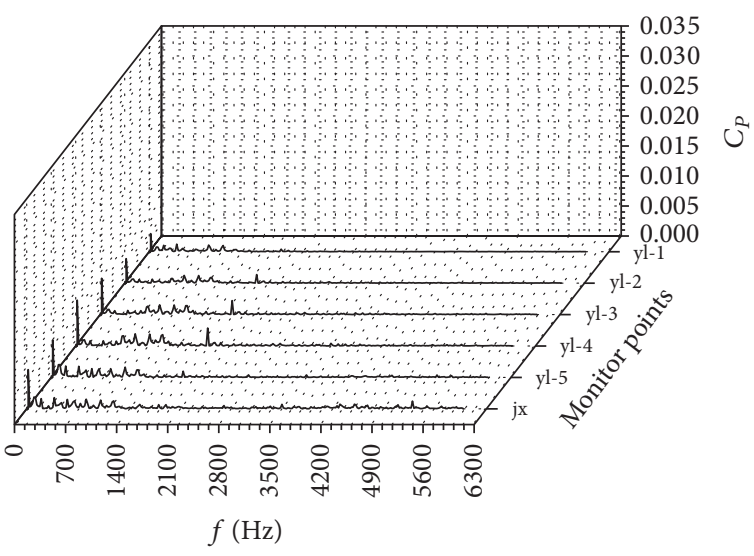

(d) $D_{2}=210.8 \mathrm{~mm}$

FIGURE 14: Pressure spectra of the pump with different impeller diameters at nominal flow rate.

where $\vec{F}_{r}$ is the radial force, $\vec{F}_{p}$ is the radial force caused by fluid pressure, and $\vec{F}_{v}$ is the radial force caused by fluid viscosity.

Figure 15 shows the vector diagram of the unsteady radial force on the impeller in the rotating frame, where the radial force is divided into two components along the $x$ - and $y$ axes. In this diagram, the coordinate of a point represents the magnitude and direction of the radial force at a specific time point. As shown in the figure, the shape of the curves narrowed while that of the vector force was normalized as impeller diameter decreased. In addition, the amplitude of the radial force weakened. In general, variations in vectors imply that a larger impeller diameter enhances rotor-stator interaction and unsteady flow characteristics (e.g., turbulence and flow separation in the impeller passage). In the present study, the bearing and seal were designed by considering the fatigue caused by the alternating forces and stresses in the impeller. Figure 16 shows the radial force frequency domain of the four impellers, where the predominant components in the force spectra are localized in the low-frequency region. In the $x$ and $y$ directions, the amplitudes are nearly the same. The findings imply that a nonuniform inflow increases radial force at a low-frequency region, thereby producing low-frequency vibrations of the shaft system.
By contrast, the maximum amplitude frequencies in the $x$ and $y$ directions of the impeller with $235.6 \mathrm{~mm}$ diameter were higher than those in the other three cases. This finding implies that the gap between the impeller and the diffuser increases even at the first trimming and then continuously affects the steady flow near the outlet. Moreover, vortex shedding caused by the inadequate flow passage developed at the impeller outlet. The model with $235.6 \mathrm{~mm}$ diameter provides the longest impeller passage among the three cutting cases, which indicates the largest area of action among unstable forces, such as vortex shedding.

\section{Conclusion}

The influence of impeller diameter on the steady state and unsteady-state characteristics of high-speed, high-powered pumps was investigated via simulation and experiments. The steady-state analysis comprised parameters, such as pump performance and hydraulic loss, whereas the unsteadystate analysis included pressure pulsation and radial force. Pressure pulsation signals were monitored by assigning six points in the impeller passage. Then, pressure spectrum characteristics were obtained after FFT. Finally, radial force values were compared. The main conclusions are summarized as follows. 


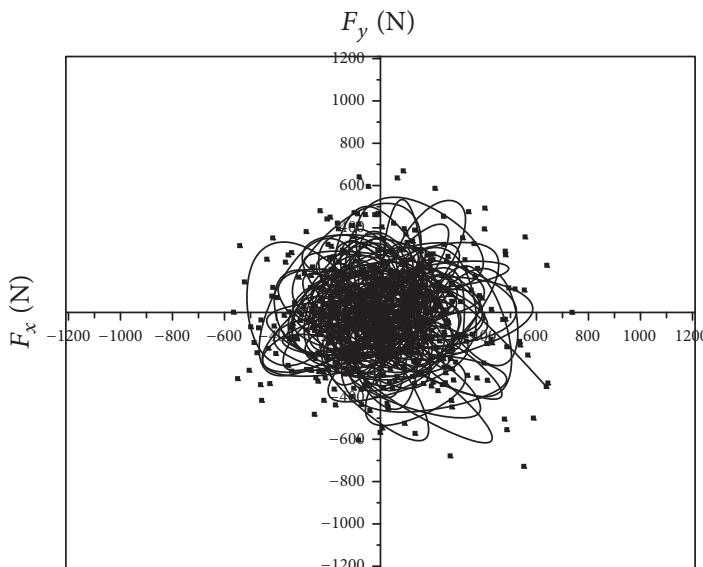

$\rightarrow$ Impeller

(a) $D_{2}=248 \mathrm{~mm}$

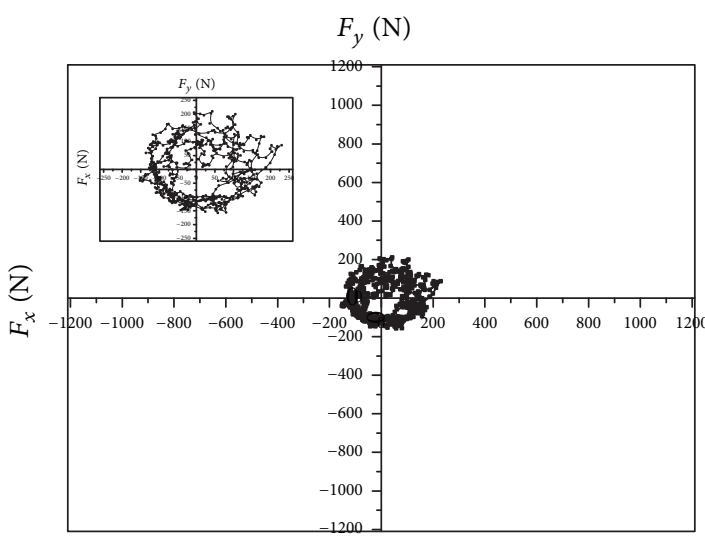

-.- Impeller

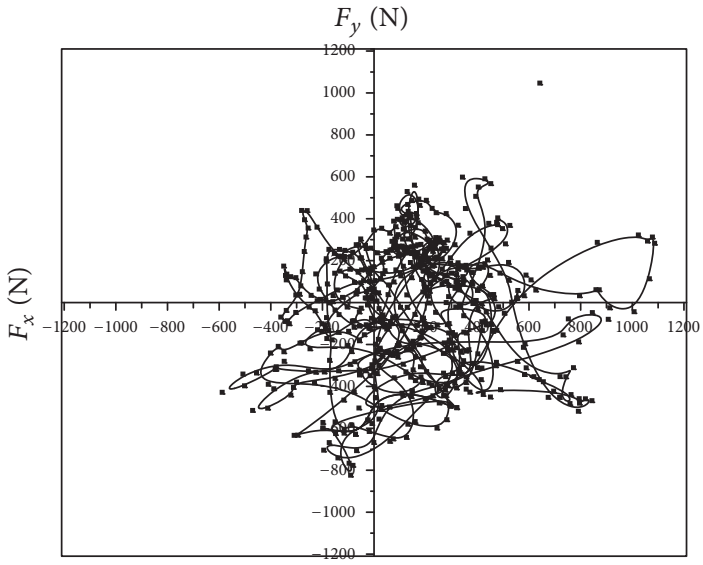

$\rightarrow$ Impeller

(b) $D_{2}=235.6 \mathrm{~mm}$

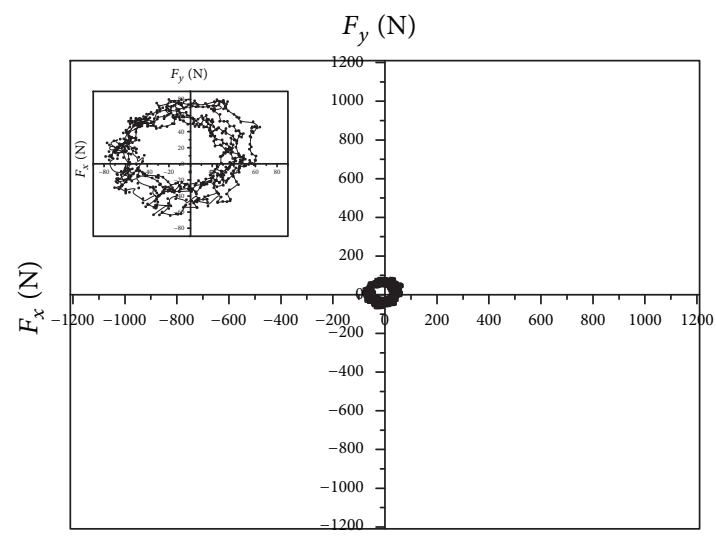

-.- Impeller

(c) $D_{2}=223.2 \mathrm{~mm}$

(d) $D_{2}=210.8 \mathrm{~mm}$

FIGURE 15: Vector diagram of the unsteady radial force at nominal flow rate.

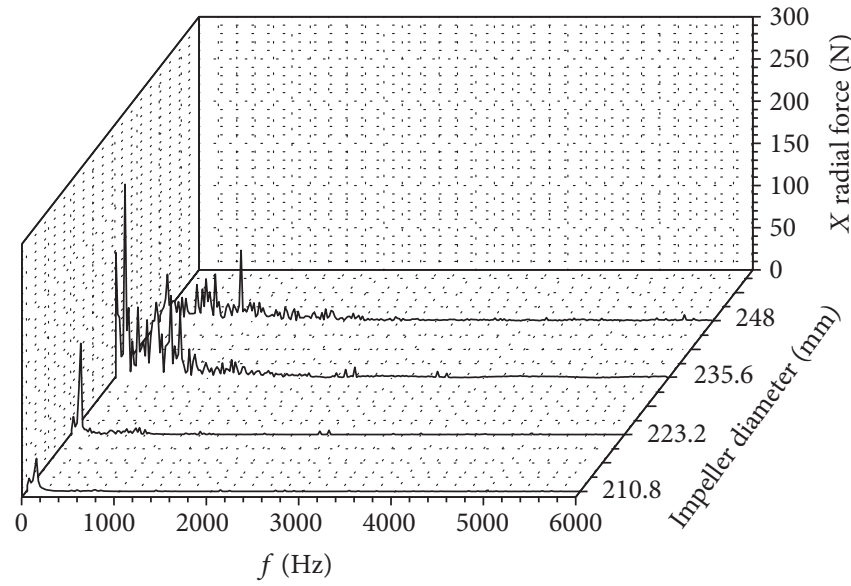

(a) $X$ radial force

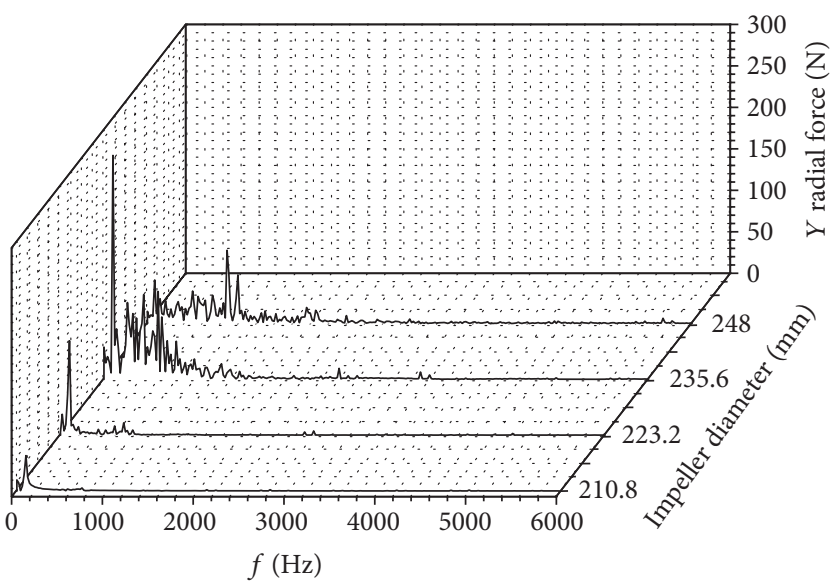

(b) $D_{2}=Y$ radial force

FIGURE 16: The radial force frequency domain of the impeller with different impeller radius. 
The numerical results were validated using the experimental data for the head, power, and efficiency values with different flow coefficients. The numerical simulation results show that changing impeller diameter can alter pump performance. As impeller diameter decreases, the head curves drop in accordance with the trimming law. The impeller with $210.8 \mathrm{~mm}$ diameter attained maximum efficiency in the nominal flow rate.

Hydraulic loss values are generally similar, except after impeller trimming. The proportion of hydraulic loss in the impeller initially decreases and then increases with nominal flow rate.

In terms of pressure pulsation in the context of the time domain, the pressure intensity in the impeller with $210.8 \mathrm{~mm}$ diameter was lower than those for the other three impellers. For the pressure spectra, the frequency band of $0-2800 \mathrm{~Hz}$ $\left(4 f_{B E F}\right)$ preserved most of the component values in all four cases. However, the differences in pressure pulsations across all four cases were apparent. For the impeller with a diameter of $223.2 \mathrm{~mm}$, pressure pulsation was evidently strong in the gap.

As a major index of pump stability, radial forces were investigated and then compared. Impeller trimming leads to variations in the $x$ and $y$ radial forces. In the case of the impeller with a diameter of $235.6 \mathrm{~mm}$, amplitude was considerably higher than those in the other three cases. As impeller diameter decreased, amplitude also decreased whereas periodicity increased.

The present work can provide significant guidance in the design of high-speed, high-powered rescue pumps. It also contributes to improving the understanding of flow characteristics. Understanding the effects of impeller diameter on pump performance, unsteady pressure, and radial force is crucial in accurately evaluating pump performance because these effects are directly related to the design of new types of pumps.

\section{Nomenclature}

$\begin{array}{ll}a_{3}: & \text { Throat height of diffuser vane } \\ a_{4}: & \text { Outlet height of diffuser vane } \\ b_{2}: & \text { Outlet width of impeller } \\ \text { Coef: } & \text { Expert coefficient, } 0.01 \\ C_{P}: & \text { Pressure pulsation coefficient } \\ C_{\mu}: & k-\varepsilon \text { turbulence model constant } \\ D_{0}: & \text { Hub diameter } \\ D_{1}: & \text { Inlet diameter of impeller } \\ D_{2}: & \text { Outlet diameter of impeller } \\ D_{3}: & \text { Base diameter of diffuser vane } \\ D_{4}: & \text { Outer diameter of diffuser vane } \\ D_{5}: & \text { Outlet diameter of diffuser vane } \\ f_{B E F}: & \text { Blade passing frequency } \\ f_{n}: & \text { Rotating frequency } \\ F_{2}: & \text { Blending functions } \\ h_{s}{ }^{+}: & \text {Dimensionless sand-grain } \\ H_{H}: & \text { roughness } \\ H_{d}: & \text { Head } \\ H_{t}: & \text { Designed head }\end{array}$

\begin{tabular}{|c|c|}
\hline$H_{\mathrm{im}}:$ & Impeller hydraulic loss \\
\hline$H_{\mathrm{si}}:$ & Numerical simulation head \\
\hline$H_{\mathrm{th}}:$ & Theoretical head \\
\hline$k:$ & Turbulent kinetic energy \\
\hline$n:$ & Rotation speed \\
\hline$n_{s}:$ & Specific speed \\
\hline$p:$ & Pressure \\
\hline$P_{k}:$ & Turbulence production \\
\hline $\bar{p}:$ & Time-averaged pressure \\
\hline$Q:$ & Flow rate \\
\hline$Q_{d}:$ & Designed flow rate \\
\hline$S_{\varphi}:$ & Sum of the body forces \\
\hline$t:$ & Time \\
\hline$u:$ & Velocity \\
\hline$u_{2}:$ & Velocity of the impeller tip \\
\hline$u^{*}:$ & Alternative velocity scale \\
\hline$y^{+}:$ & Nondimensional wall distance \\
\hline$y^{*}:$ & Alternative distance \\
\hline$Z_{1}, Z_{2}$ & $\begin{array}{l}\text { Blade number of impeller, diffuser } \\
\text { vane }\end{array}$ \\
\hline$\alpha_{d 3}:$ & Inlet angle of diffuser vane \\
\hline$\beta_{i 2}:$ & Outlet blade angle of impeller \\
\hline$\beta^{\prime}, \alpha_{1}, \beta_{1}, \sigma_{k 1}$, & Turbulence constants \\
\hline $\begin{array}{l}\sigma_{\omega 1}, \sigma_{k 2}, \sigma_{\omega 2}, \alpha_{2}, \\
\beta_{2}, \alpha_{3}, \beta_{3}, \sigma_{\omega 3}, \beta_{2}, \\
\alpha_{3}, \beta_{3}, \sigma_{\omega 3}:\end{array}$ & \\
\hline$\varepsilon:$ & Dissipation rate \\
\hline$\eta:$ & Efficiency \\
\hline$\mu:$ & Molecular viscosity \\
\hline$\mu_{\text {eff }}:$ & Effective viscosity \\
\hline$\varphi:$ & Time varying component \\
\hline$\rho:$ & Density \\
\hline$\kappa:$ & Von Karman constant \\
\hline$\vec{F}_{r}:$ & Radial force vector \\
\hline$\vec{F}_{p}:$ & $\begin{array}{l}\text { Radial force vector caused by } \\
\text { pressure }\end{array}$ \\
\hline$\vec{F}_{v}:$ & $\begin{array}{l}\text { Radial force vector caused by } \\
\text { viscosity }\end{array}$ \\
\hline$\vec{U}:$ & Vector of velocity \\
\hline$\Delta n:$ & Distance between grid points \\
\hline$\Gamma_{\text {eff }}:$ & Effective diffusivity. \\
\hline
\end{tabular}

\section{Conflicts of Interest}

The authors declare that there are no conflicts of interest regarding the publication of this paper.

\section{Acknowledgments}

The authors disclosed receipt of the following financial support for the research, authorship, and/or publication of this article: this work was partly supported by the grants of National Natural Science Foundation of China (no. 11602097, no. 51509111, and no. 2013BAK06B02), China Postdoctoral Science Foundation (2015M581734, 2017M611721), Postdoctoral Science Foundation of Jiangsu Province (1601228C), the Advanced Talent Foundation of Jiangsu University 
(15JDG052), the Open Research Subject of Key Laboratory of Fluid and Power Machinery, Ministry of Education, Xihua University (szjj2015-017, szjj2017-094), Sichuan Provincial Key Lab of Process Equipment and Control (GK201614), the association innovation fund of production, learning, and research (BY2016072-01), and a project funded by the Priority Academic Program Development of Jiangsu Higher Education Institutions (PAPD).

\section{References}

[1] S. N. Dong, "Current situation and prospect of coal mine geological guarantee technologies to improve safety and efficiency," Coal Science \& Technology, vol. 35, no. 3, pp. 1-5, 2007.

[2] S. P. Peng, "Present study and development trend of the deepen coal resource distribution and mining geologic evaluation," Coal, vol. 17, no. 2, pp. 1-11, 2008.

[3] D. W. Jin, Q. S. Liu, and L. Wang, "Development and prospect of coal deposit hydrogeology," Coal Geology \& Exploration, vol. 37, no. 5, pp. 28-31, 2009.

[4] Q. Wu, "Progress, problems and prospects of prevention and control technology of mine water and reutilization in China," Journal of the China Coal Society, vol. 39, no. 5, pp. 795-805, 2014.

[5] J. Zhu, H. Banjar, Z. Xia, and H.-Q. Zhang, "CFD simulation and experimental study of oil viscosity effect on multi-stage electrical submersible pump (ESP) performance," Journal of Petroleum Science and Engineering, vol. 146, pp. 735-745, 2016.

[6] J. Feng, F.-K. Benra, and H. J. Dohmen, "Investigation of periodically unsteady flow in a radial pump by CFD simulations and LDV measurements," Journal of Turbomachinery, vol. 133, no. 1, Article ID 011004, pp. 1-4, 2011.

[7] H.-X. Cui, K. Feng, H.-L. Li, and J.-H. Han, "Response characteristics analysis and optimization design of load sensing variable pump," Mathematical Problems in Engineering, vol. 2016, Article ID 6379121, 10 pages, 2016.

[8] F. Yang, H.-R. Zhao, and C. Liu, "Improvement of the efficiency of the axial-flow pump at part loads due to installing outlet guide vanes mechanism," Mathematical Problems in Engineering, vol. 2016, Article ID 6375314, 10 pages, 2016.

[9] L. J. Barrios, S. L. Scott, and K. K. Sheth, "ESP technology maturation: subsea boosting system with high GOR and viscous fluids," in Proceedings of the SPE Annual Technical Conference and Exhibition 2012: Unconventional Wisdom (ATCE '12), vol. 2, pp. 1580-1601, October 2012.

[10] C. Maitelli, V. Bezerra, and W. D. Mata, "Simulation of flow in a centrifugal pump of ESP systems using computational fluid dynamics," Brazilian Journal of Petroleum \& Gas, vol. 4, pp. 1-9, 2010.

[11] R. Barrio, J. Parrondo, and E. Blanco, "Numerical analysis of the unsteady flow in the near-tongue region in a volute-type centrifugal pump for different operating points," Computers \& Fluids, vol. 39, no. 5, pp. 859-870, 2010.

[12] L. Yun, Z. Rongsheng, W. Dezhong, Y. Junlian, and L. Tianbin, "Numerical and experimental investigation on the diffuser optimization of a reactor coolant pump with orthogonal test approach," Journal of Mechanical Science and Technology, vol. 30, no. 11, pp. 4941-4948, 2016.

[13] J. Skrzypacz, "Investigating the impact of multi-piped impellers design on the efficiency of rotodynamic pumps operating at ultra-low specific speed," Chemical Engineering and Processing: Process Intensification, vol. 86, pp. 145-152, 2014.

[14] A. Boccazzi, R. Sala, and P. Gaetani, "Flow field in the vaned diffuser of a centrifugal pump at different vane setting angles," Asme-Jsme-Ksme Joint Fluids Engineering Conference, vol. 134, no. 3, pp. 369-380, 2011.

[15] Z. Gao, W. Zhu, L. Lu, J. Deng, J. Zhang, and F. Wuang, "Numerical and experimental study of unsteady flow in a large centrifugal pump with stay vanes," Journal of Fluids Engineering, vol. 136, no. 7, Article ID 071101, 2014.

[16] N. Zhang, M. Yang, B. Gao, Z. Li, and D. Ni, "Experimental investigation on unsteady pressure pulsation in a centrifugal pump with special slope volute," Journal of Fluids Engineering, vol. 137, no. 6, Article ID 061103, 2015.

[17] J. Pei, S. Yuan, F.-K. Benra, and H. J. Dohmen, "Numerical prediction of unsteady pressure field within the whole flow passage of a radial single-blade pump," Journal of Fluids Engineering, vol. 134, no. 10, Article ID 101103, 2012.

[18] J. Pei, S.-Q. Yuan, X.-J. Li, and J.-P. Yuan, "Numerical prediction of 3-D periodic flow unsteadiness in a centrifugal pump under part-load condition," Journal of Hydrodynamics, vol. 26, no. 2, pp. 257-263, 2014.

[19] J. Pei, S.-Q. Yuan, J.-P. Yuan, and W.-J. Wang, “The influence of the flow rate on periodic flow unsteadiness behaviors in a sewage centrifugal pump," Journal of Hydrodynamics, vol. 25, no. 5, pp. 702-709, 2013.

[20] G. Singh and J. W. Mitchell, "Energy savings: From pump impeller trimming," ASHRAE Journal, vol. 51, no. 11, pp. 34-44, 2009.

[21] L. M. Tsang, "A theoretical account of impeller trimming of the centrifugal pump," Proceedings of the Institution of Mechanical Engineers, Part C: Journal of Mechanical Engineering Science, vol. 206, no. 3, pp. 213-214, 1992.

[22] G. Singh, Energy and Environmental Benefits of Pump Impeller Trimming in Commercial Building Heating and Cooling Systems [PhD. Thesis], University of Wisconsin-Madison, 1997.

[23] P. Singh and F. Nestmann, "Internal hydraulic analysis of impeller rounding in centrifugal pumps as turbines," Experimental Thermal and Fluid Science, vol. 35, no. 1, pp. 121-134, 2011.

[24] S. V. Jain, A. Swarnkar, K. H. Motwani, and R. N. Patel, "Effects of impeller diameter and rotational speed on performance of pump running in turbine mode," Energy Conversion and Management, vol. 89, no. 1, pp. 808-824, 2015.

[25] R. Barrio, E. Blanco, J. Parrondo, J. González, and J. Fernández, "The effect of impeller cutback on the fluid-dynamic pulsations and load at the blade-passing frequency in a centrifugal pump," Journal of Fluids Engineering, vol. 130, no. 11, pp. 1111021-11110211, 2008.

[26] M. Šavar, H. Kozmar, and I. Sutlović, "Improving centrifugal pump efficiency by impeller trimming," Desalination, vol. 249, no. 2, pp. 654-659, 2009.

[27] Y. Wang and J. Q. Liu, "Impeller trim of super-low specific speed centrifugal pump based on numerical simulation of 3D flow field," Transactions of the Chinese Society of Agricultural Machinery, vol. 43, no. 5, pp. 79-83, 2012.

[28] D. S. Zhang, C. Wang, and W. D. Shi, "Establishment and experiment of impeller cutting law of double channel pump," Transactions of the Chinese Society for Agricultural Machinery, vol. 45, no. 1, pp. 73-78, 2014.

[29] P. Zhou, J. Tang, J. Mou, and B. Zhu, "Effect of impeller trimming on performance," World Pumps, vol. 2016, no. 9, pp. 38-41, 2016. 
[30] M. A. Yates and I. Weybourne, "Improving the energy efficiency of pumping systems," Iwa Publishing, vol. 50, no. 2, pp. 101-111, 2001.

[31] T. Q. Luo, Z. X. Cheng, and Y. Z. Xie, Hydrodynamics, China Machine Press, Beijing, China, 2007.

[32] C. G. Lu, Numerical Methods in Hydrodynamics, Science Press, Beijing, China, 2014.

[33] X. F. Guan, Modern Pumps Theory and Design, China Astronautic Press, 2011.

[34] “ANSYS User Manual 14.0," ANSUS Inc, 2011. 


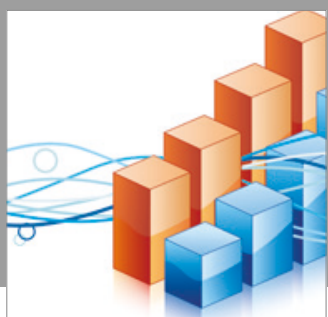

Advances in

Operations Research

vatersals

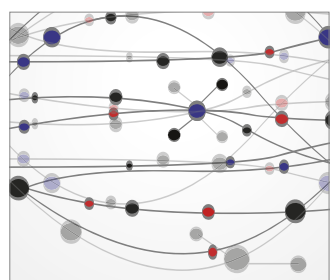

\section{The Scientific} World Journal
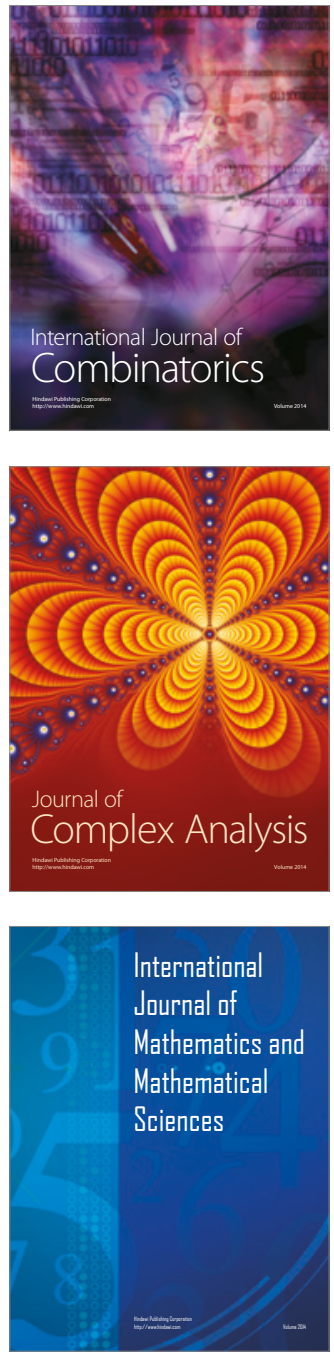
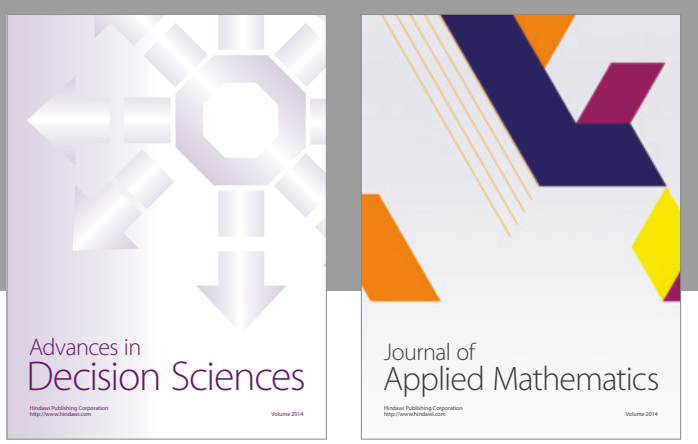

Algebra

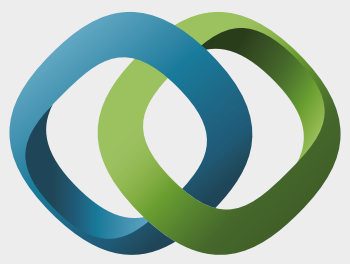

\section{Hindawi}

Submit your manuscripts at

https://www.hindawi.com
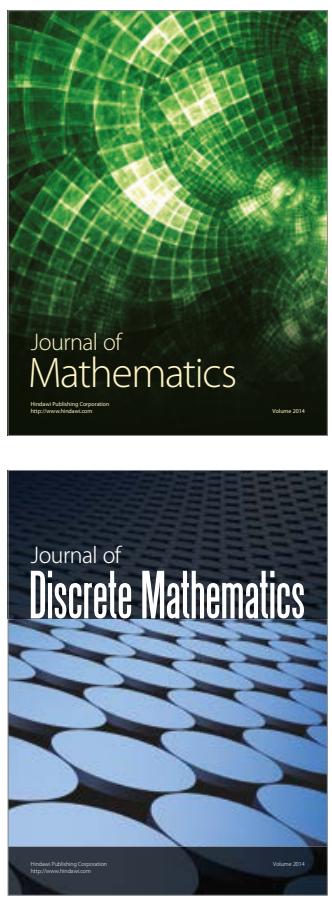

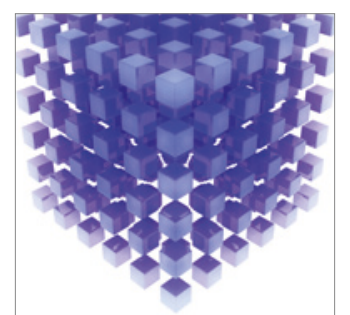

Mathematical Problems in Engineering
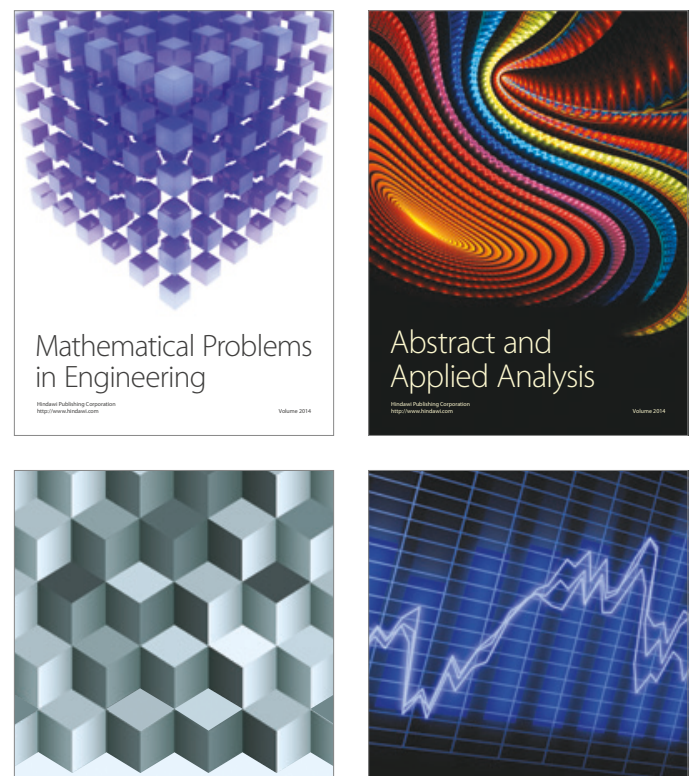

Journal of

Function Spaces

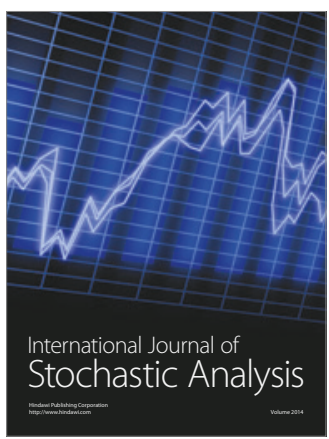

Probability and Statistics
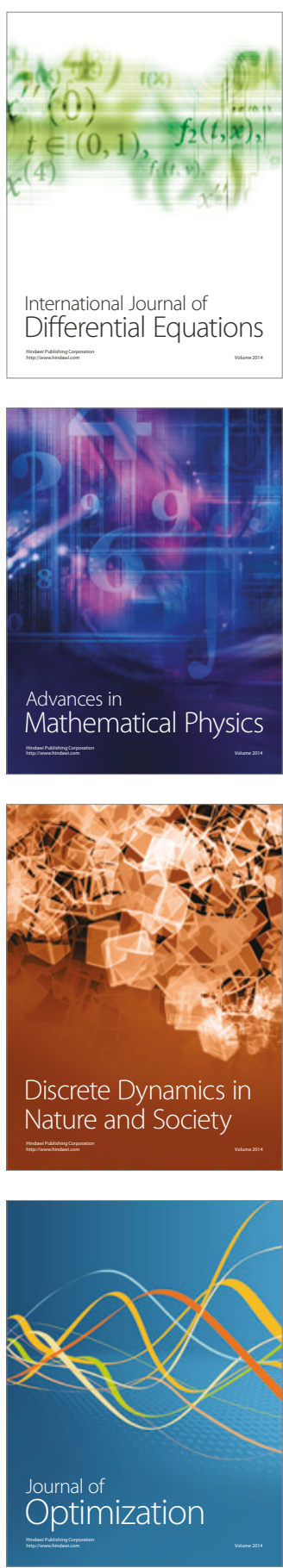